AL-QANTARA

XL 1, enero-junio 2019

pp. $135-183$

ISSN 0211-3589

https://doi.org/10.3989/alqantara.2019.005

\title{
La Mezquita-Catedral de Córdoba. Fuentes gráficas hasta 1850
}

\author{
The Mosque-Cathedral of Córdoba. \\ Graphic Sources up to 1850
}

\author{
Antonio Gámiz Gordo \\ Universidad de Sevilla \\ https://orcid.org/0000-0001-6188-3167
}

La Mezquita-Catedral de Córdoba cuenta con un rico legado de imágenes hasta la llegada de la fotografía a mediados del XIX que constituyen una destacada fuente documental para la investigación. Tras una amplia labor de rastreo y localización de dichas imágenes, se aportan referencias sobre sus autores, contexto y técnicas, valorando su fiabilidad o precisión gráfica. Las primeras conocidas corresponden a tiempos cristianos, destacando dos panorámicas urbanas de la segunda mitad del XVI, una de ellas objeto de plagios con una notable difusión en Europa. Los primeros planos a escala del monumento conservados son del XVIII y las primeras vistas interiores de finales de ese siglo. En la primera mitad del XIX se produjeron abundantes imágenes de viajeros y artistas, algunas muy bellas y publicadas con gran éxito editorial. Los documentos gráficos reseñados se presentan agrupados según su autoría y orden cronológico: primeras imágenes simbólicas (desde 1360), Wyngaerde (1567), Civitatis (h. 1585-1617), copias del Civitatis (s. XVII-XVIII), Baldi (1668), óleo anónimo (1741), imágenes esquemáticas (s. XVIII), dibujo colección Vázquez Venegas (1752), planos Académicos (1767-1804), Swinburne (1775-1779), Karwinsky y Rillo (1811), Laborde (h. 1800-1812), Murphy (1802-1813), Bacler d'Able (h. 1820), Taylor (h. 1826-1832), Ford (1831), Lewis (1832-
The vast graphic legacy illustrating the Mosque-Cathedral of Córdoba prior to the rise of paper photography around 1850 , constitutes an important documentary source for research. After an extensive work of tracing and identification of those images, the present work provides accurate references upon their authors, contexts and techniques, assessing their trustability or graphic precision. The earliest images known correspond to Christian times, where two urban panoramic views should be highlighted, one of them widely plagiarized and disseminated in Europe. The first scale drawings of the building still preserved date back to the $18^{\text {th }}$ century, while the first interior views are from the end of the same century. In the first half of the $19^{\text {th }}$ century there was a large production of images made by travelers and artists, some of them of great beauty, and published with great editorial success. The graphic documents highlighted here are compiled according to authorship and chronological order: first symbolic images (from 1360), Wyngaerde (1567), Civitatis (h. 1585-1617), copies of Civitatis $\left(17^{\text {th }}-18^{\text {th }}\right.$ c.), Baldi (1668), anonymous oil painting (1741), schematic images $\left(18^{\text {th }} \mathrm{c}\right.$.), drawing from Vázquez Venegas' collection (1752), Academic plans (1767-1804), Swinburne (1775-1779), Karwinsky and Rillo (1811), Laborde (c. 1800-1812), Murphy (1802-1813), Bacler d'Able (c. 1820), Taylor

Copyright: (C) 2019 CSIC. Este es un artículo de acceso abierto distribuido bajo los términos de la licencia de uso y distribución Creative Commons Reconocimiento 4.0 Internacional (CC BY 4.0). 
1836), Prangey (1832-1837), Gail (h. 183237), Roberts (1833-1839), Dauzats (h. 18361838), Chapuy (h. 1838-1842), Villaamil (h. 1838-1844), Bossuet (h. 1841-1855), Gerhardt (h. 1849-1851), Guesdon (1853), Parcerisa (1855) y Los Monumentos Arquitectónicos (h. 1852-1881).

Palabras clave: Córdoba; Mezquita-Catedral; imágenes; vistas; dibujos; planos. (c. 1826-1832), Ford (1831), Lewis (18321836), Prangey (1832-1839), Gail (c. 1832 37), Roberts (1833-1837), Dauzats (c. 1836-1838), Chapuy (c. 1838-1842), Villaamil (c. 1838-1844), Bossuet (c. 1841-1855), Gerhardt (c. 1849-1851), Guesdon (1853), Parcerisa (1855), and Los Monumentos Arquitectónicos (c. 1852-1881).

Key words: Córdoba; Mosque-Cathedral; images; views; drawings; plans.

La Mezquita-Catedral de Córdoba ha sido plasmada en numerosas imágenes de diversos autores y distintas épocas que constituyen un corpus de gran interés para la investigación patrimonial ${ }^{1}$, sobre todo si se contrastan con la propia realidad arquitectónica o con otras fuentes histórico-literarias, tanto musulmanas como cristianas ${ }^{2}$. En la presente investigación se plantea una aproximación al conjunto de dichas fuentes gráficas hasta mediados del siglo XIX, cuando tuvo lugar el importante auge de la fotografía como registro documental.

Para ello se ha realizado un laborioso rastreo en archivos, museos, catálogos de subastas, diccionarios de artistas, colecciones particulares y en una amplia bibliografía, con objeto de localizar los más significativos documentos gráficos sobre el monumento. No son muchos los estudios que han reunido imágenes sobre la Mezquita-Catedral a lo largo de su historia, aunque algunas se han reproducido en reiteradas ocasiones, resultando conocidas más allá de nuestras fronteras. Cabe destacar el libro de Nieto Cumplido y Luca de Tena, La Mezquita de Córdoba: planos y dibujos (1992) con una amplia recopilación que no incluye vistas urbanas ni de interiores; y el libro de Cosano Moyano, Iconografía de Córdoba (1999) que comprende imágenes de la ciudad junto a estampas de devoción religiosa ${ }^{3}$. Asimismo, deben mencionarse

${ }^{1}$ El presente trabajo se enmarca en una línea de investigación que trata de documentar y analizar gráficamente el patrimonio arquitectónico, urbano y paisajístico como forma de conocerlo, preservarlo y difundir su conocimiento.

2 Sobre las fuentes histórico-literarias de la Mezquita-Catedral véase Nieto Cumplido, La Catedral... p. 25-32 y 319-326. Véase también: Calvo Capilla, "Primeras mezquitas de Al-Andalus a través de las fuentes árabes", pp. 166-177.

${ }^{3}$ Nieto Cumplido y Luca de Tena, La Mezquita...; Cosano Moyano, Iconografia...; véase también: Báez, Imágenes y visiones... sobre imágenes de Córdoba hasta nuestros días. 
los artículos de Gámiz Gordo y García Ortega citados en bibliografía y algunos repertorios bibliográficos de viajeros con referencias de imágenes, como Foulche-Delbosch u otros.

Tras localizar cada imagen se han reunido datos básicos sobre su contexto, atendiendo a los intereses y formación de sus autores, que reflejaron su particular visión con distintas técnicas o intenciones, según sus habilidades o dedicación. Debe advertirse que frente a la fiel descripción de la fotografía, para interpretar adecuadamente cada dibujo es necesario valorar su precisión gráfica o grado de fiabilidad, considerando que muchos fueron convertidos en grabados o litografías con ciertas manipulaciones. Así, no debe darse por supuesta la validez documental de los datos reflejados en cualquier dibujo, pues siempre son visiones personales más o menos acertadas y con distintos grados de fidelidad respecto a la realidad representada.

Finalmente, para presentar las referencias sobre las imágenes reunidas se han ordenado agrupadas por autores y siguiendo un orden cronológico.

\section{Primeras imágenes simbólicas (desde 1360)}

No se conocen imágenes de época islámica de la ciudad de Córdoba, ni de su Mezquita. Entre los primeros testimonios gráficos cabe mencionar algunas descripciones genéricas de viajeros o cartógrafos, a veces acompañadas con mapas que respondían a la necesidad de conocer o controlar distintos territorios ${ }^{4}$.

La primera representación de la Mezquita-Catedral conocida es un sello de la ciudad de Córdoba en tiempos cristianos, datado hacia 1360, que se conserva en el Archivo de la Casa de Medinaceli en Sevilla (Casa de Pilatos) y que fue estudiado por Julio Caro Baroja ${ }^{5}$. Tiene

${ }^{4}$ Como ejemplo cabe destacar la geografía universal de al-Idrisi (1099-1166) realizada por encargo de Roger II en Sicilia (h. 1154) junto a mapas cuyas copias se conservan en la Biblioteca Nacional de París (h. 1300) en la Bodleian Library de Oxford (1456) y en Estambul (siglo XIV). Piqueras y Fansa, "La península Ibérica en el gran atlas de al-Idrisi", pp. 465-477.

5 Caro Baroja "La ciudad de Córdoba desde la orilla izquierda...", pp. 197-ss. Cosano Moyano, Iconografía... pp. 245-247. Nieto Cumplido y Luca de Tena, La Mezquita... $\mathrm{n}^{\circ}$ 127,128 y 345 . 
forma circular, en su anverso incluye un león y en el reverso una representación simbólica de la rueda hidráulica de la Albolafia, junto al puente romano; más atrás aparecen la muralla y la Mezquita con su alminar islámico, contrafuertes, ajimeces y lucernarios, así como las palmeras del patio de los Naranjos que emergen sobre sus cubiertas.

Otro sello medieval datado hacia 1440, conservado en el Museo Franciscano de Martos (Jaén), también tiene forma circular e incluye el puente y la Mezquita-Catedral muy idealizada, con dos palmeras a ambos lados de su alminar6.

Un escudo catedralicio anónimo datado en el siglo XVI representa la fachada del monumento y sobre ella su alminar con pequeñas ventanas, rematado por una gran campana ${ }^{7}$. Dicha torre también fue representada de forma esquemática en azulejos y en relieves incluidos en pesas que se conservan en el Museo Arqueológico de Córdoba y que no tienen una datación muy precisa ${ }^{8}$. Además aparece en relieves escultóricos ubicados en la puerta de Santa Catalina, trazada por Hernán Ruiz el Joven, en los que figura la puerta del Perdón en su estado previo a los añadidos cristianos 9 .

Otra representación totalmente imaginaria de la ciudad de Córdoba fue incluida en la obra del clérigo y cosmógrafo sevillano Pedro de Medina (1493-1567) Libro de las Grandezas y Cosas Memorables de España, publicada en Sevilla en 1548 por el impresor Doménico de Robertis ${ }^{10}$. Junto a su descripción se incluyó una xilografía en la que aparece un castillo junto a un río, usándose un dibujo idéntico para representar ciudades como Jaén, Écija, Jerez, Antequera u otras en la misma publicación. 248.

${ }^{6}$ Nieto Cumplido, La Catedral... pp. 169 y 579. Cosano Moyano, Iconografía... p.

7 Nieto Cumplido y Luca de Tena, La Mezquita... n ${ }^{\circ} 374$. Cosano Moyano, Iconografia... pp. 288 y 536.

${ }^{8}$ Nieto Cumplido, La Catedral... p. 171.

9 Nieto Cumplido y Luca de Tena, La Mezquita... n ${ }^{\circ}$ 294. Nieto Cumplido La Catedral... p. 161. Cosano Moyano, Iconografia... pp. 289-290.

10 Se volvió a publicar en 1549 en Sevilla, en 1566 en Alcalá de Henares y en 1590 con el título: Primera y Segunda Parte de las Grandezas y cosas notables de España, corregida y ampliada por Diego Pérez de Messa y reeditada en 1595. 


\section{La panorámica de Anton van der Wyngaerde (1567)}

Con la llegada del Renacimiento, las vistas de ciudades cobraron mayor precisión o verosimilitud, hasta que a finales del siglo XVIII se empezó a generalizar el uso de sistemas de representación geométrica y también artilugios ópticos con los que se produjeron dibujos más objetivos y precisos.

Una de las más tempranas y excepcionales vistas de Córdoba, conservada en el Victoria and Albert Museum de Londres ${ }^{11}$, fue dibujada en 1567 por el pintor flamenco Anton van den Wyngaerde (h. 15251571). No se conocen con certeza los fines concretos para los que dicho artista realizó sus minuciosas vistas de medio centenar de ciudades españolas, que fueron enviadas a los Países Bajos, posiblemente para una publicación que no llegó a realizarse, permaneciendo inéditas y dispersas hasta su estudio por Richard Kagan ${ }^{12}$ (1986) y Monserrat Galera $(1998)^{13}$.

Wyngaerde realizó una amplia panorámica de Córdoba con plumilla y aguada, aportando abundantes y fieles detalles de gran valor documental, casi notarial. El punto de vista se situó en el sur de la ciudad, hacia el camino de Granada, ligeramente sobreelevado, incluyendo en primer plano edificios del arrabal de la Saqunda y la torre de la Calahorra. En el Guadalquivir, junto al puente romano, aparecen pequeñas embarcaciones, molinos fluviales y la noria de la Albolafia, con abundante vegetación en su entorno. En el casco histórico muchas iglesias sobresalen entre el caserío urbano, según se encontraban por entonces ${ }^{14}$, destacando de forma imponente el gran volumen de la que fue Mezquita aljama, con la fábrica catedralicia emergiendo desde su interior. Wyngaerde plasmó dicho proceso de construcción en marcha, dibujando incluso los lucernarios en las cubiertas, los almenados que rematan los muros de las fachadas, o el alminar de Abderramán III, que

11 "Museum number: 8455:6. Gallery location: Prints \& Drawings Study Room, level $\mathrm{F}$, case 95 , shelf $\mathrm{H}$, box 54 ". La primera página del álbum incluye nota manuscrita que dice: "The following drawings were executed at the expense of famous printer, Plantin of Antwerp..." o sea, los dibujos fueron ejecutados a expensas del famoso impresor Cristóbal Plantino o Plantin de Antwerp, que mantuvo constantes relaciones con Felipe II.

${ }_{12}$ Kagan (dir.), Ciudades del siglo de oro...

13 Galera i Monegal, Antoon van den Wijngaerde...

${ }^{14}$ Gámiz Gordo y García Ortega, "Las iglesias cordobesas en tres imágenes...”, pp. 158-165. 
contaba entonces con un rudimentario remate cristiano y una gran campana. Además, según Nieto Cumplido, se distingue el desaparecido sabat por el que el soberano pasaba desde el Alcázar a la Mezquita para la oración, con tres ventanas en su costado sur y la cubierta levemente $\operatorname{arqueada}^{15}$.

\section{La vista del Civitatis Orbis Terrarum (h. 1585-1617)}

Una vista titulada "Corduba", de autor desconocido y con cierto parecido a la de Wyngaerde, se incluyó en una importante obra que suele conocerse por el nombre del primero de sus seis volúmenes, Civitatis Orbis Terrarum ${ }^{16}$, publicados entre 1572 y 1617 en Amberes y Colonia, con cerca de quinientas cincuenta vistas urbanas. Su principal promotor, George Braun (1541-1622), recopiló dibujos y textos sobre ciudades de Europa, próximo Oriente, el norte de África y parte de la América española. Frans Hogenberg (1535-1590) reelaboró y unificó el estilo de los dibujos disponibles para ejecutar los grabados y posiblemente revisó los textos adjuntos a cada vista. En veintinueve de sus láminas aparecen unas cuarenta y tres vistas de ciudades de España, de las que treinta y dos corresponden a Andalucía, casi todas basadas en dibujos del joven pintor Joris Hoefnagel (1542-1501), que recorrió nuestro país entre 1563 y 1567.

Córdoba y el Escorial son las únicas vistas españolas incluidas entre las cincuenta y ocho láminas del tomo VI, Praecipuarum totius mundi urbium (1617). Al contrario que los dibujos españoles de Wyngaerde, que no llegaron a publicarse, el Civitatis tuvo un gran éxito editorial y hacia 1624 había cerca de cuarenta y siete ediciones. El tomo VI se reeditó en latín $(1617,1618)$, francés $(1618)$ y alemán $(1618)^{17}$.

15 Nieto Cumplido, La Catedral... p. 256.

${ }^{16}$ Braun y Hogenberg (ed.), Civitates Orbis Terrarum (6 tomos). Los títulos, lugares y fechas de la primera edición, así como número de láminas en cada tomo son: tomo I, $\mathrm{Ci}$ vitates Orbis Terrarum, Colonia y Amberes 1572 (59 láminas); tomo II: De praecipus totius universi urbibus. Liber secundus, Colonia 1575 (59 láminas); tomo III: Urbium praecipuarum totius mundi, Colonia 1581 (59 láminas); tomo IV: Urbium praecipuarum totius mundi, Colonia 1588 (59 láminas); tomo V: Urbium praecipuarum mundi theatrum, Colonia 1598 (69 láminas); tomo VI: Praecipuarum totius mundi urbium. Colonia 1617 (58 láminas).

${ }^{17}$ Skelton, Georg Braun - Frans Hogenberg... 
La vista de Córdoba se ha atribuido a Hoefnage ${ }^{18}$ a pesar de no estar firmada, por haber sido éste el autor de otras vistas españolas. Podría pensarse que fue plagiada de la vista de Wyngaerde, pues ambas tienen similar punto de vista sobreelevado y se parecen mucho en sus primeros planos. Aunque la vista del Civitatis está bastante menos detallada y se omiten importantes edificios, en el entorno del Alcázar (que Wyngaerde identificó como "El alcaçar de la Villa") aparece el rótulo "L. Stabulum Regium", o sea, las Caballerizas Reales, fundadas en 1570 por orden de Felipe II $^{19}$. Según dicho dato el dibujo del Civitatis no pudo ser elaborado por Hoefnagel ni por Wyngaerde, pues las rutas de ambos por España concluyeron en 1567, y se realizaría por un autor desconocido después de 1570.

Debe destacarse que cuando se publicó el tomo VI en 1617, ya habían fallecido los promotores de la publicación, excepto Braun, cuyo nombre no figura en éste, pero Abraham Hogenberg, hijo de Frans, continuó reeditando los seis volúmenes. Tras su muerte, el editor de mapas Johannes Janssonius de Ámsterdam compró las planchas y añadió algunas, reagrupándolas geográficamente en ocho libros. El tomo de España, titulado Theatrum In quo visuntur Illustriores Hispaniae Urbes... ${ }^{20}$ se publicó en 1657 con sesenta estampas, y hubo una edición posterior en holandés en $1682^{21}$.

Algunos grabados se modificaron porque las planchas metálicas estarían ya deterioradas por su uso o tendrían roturas que obligaron a recortarlas o rediseñarlas. En el caso de Córdoba se conocen dos variantes de la misma vista. Una versión publicada en 1617 y en 1657 incluye dos cartelas arriba (izquierda y derecha) mientras que en otra versión menos conocida esas cartelas desaparecen y la leyenda se sitúa en un cajetín que ocupa toda la parte inferior ${ }^{22}$ (Fig. 1). En éste se indica que fue editada por privilegio de Sixto V, que fue el Papa $\mathrm{n}^{\circ} 227$ de la Iglesia Católica entre 1585 y 1590, por lo que debió estamparse hacia

${ }^{18}$ Cosano Moyano, Iconografia... pp. 46-47.

19 Gámiz Gordo y García Ortega, "Vistas del Alcázar de los Reyes Cristianos...”, pp. 4-19.

20 Janssonius, Theatrum In quo visuntur..

21 Janssonius, Toonel der vermaarste...

${ }^{22}$ Incluye escudo de la Casa de Aguilar y se dedica a Luis Fernández de Córdoba y de la Cerda. Biblioteca Digital Hispánica (Inv. estampas no 19643 bis) [http://bdh.bne.es/ bnesearch/detalle/bdh0000020590] [consultado 2-10-2017] 


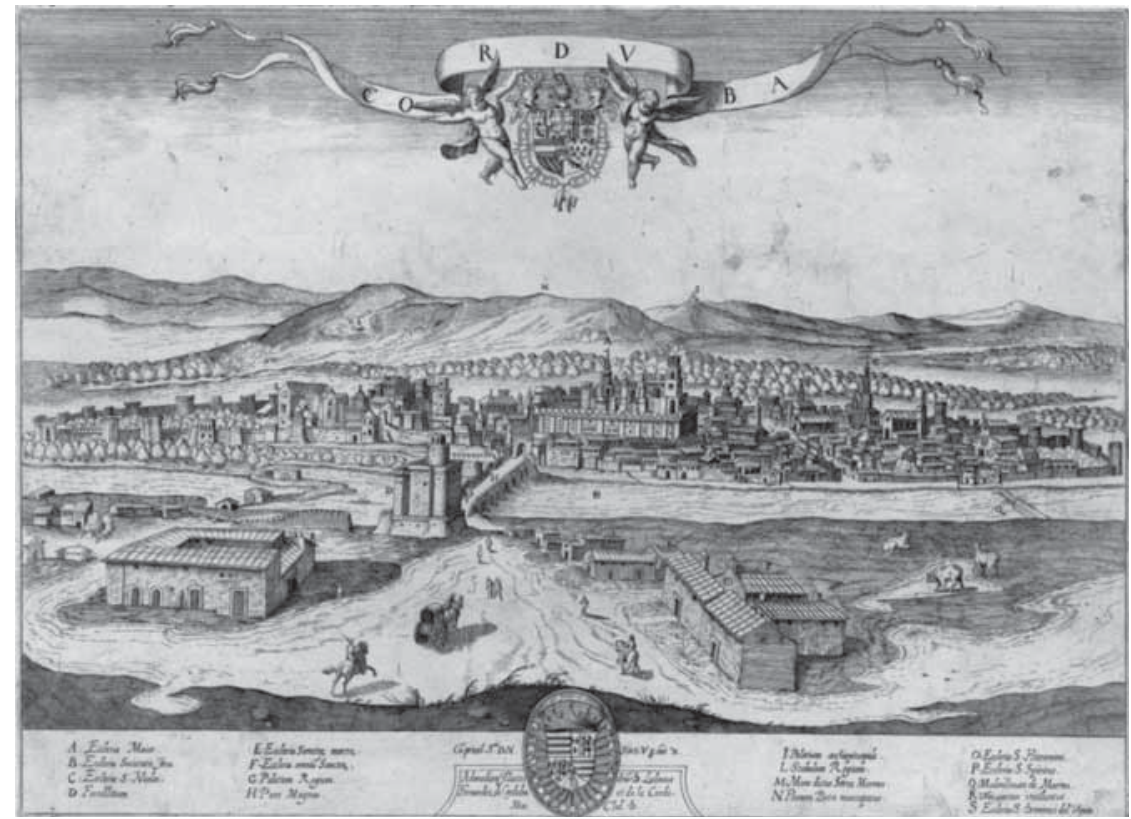

Fig. 1. Anónimo, h. 1585-1590: Córdoba (col. particular)

dichos años, antes que la otra versión citada. En ambas la representación de la Mezquita-Catedral es igual y tiene cierto parecido a la vista de Wyngaerde, aunque resulta mucho más esquemática y menos precisa en sus detalles.

\section{Copias del Civitatis (siglos XVII y XVIII)}

Tras las citadas vistas, durante un prolongado tiempo apenas hubo imágenes novedosas sobre Córdoba o su Mezquita-Catedral y muchas publicaciones se limitaron a plagiar con desigual acierto la vista del Civitatis, junto a diversas ciudades de la misma obra u otras publicadas por el francés Louis Meunier hacia 1665-1668 23 . Al tratarse de copias, su valor documental resulta limitado y su principal interés radica en la importante difusión que tuvieron en el contexto cultural europeo.

${ }^{23}$ Gámiz Gordo, Alhambra. Imágenes... pp. 107-153. 
La imagen cordobesa del Civitatis fue plagiada de forma muy esquemática por Francisco Valegio (1560-?) (a veces escrito Valesio, Valezo o Valeggio) en Raccolta di le piu illustri e famose cità di tutto il mondo $(1625)^{24}$, con el título "Corduba. In Hispania fertilis atque nob.", compartiendo lámina con otra vista de la ciudad de "Martia". Se volvió a publicar en la obra de Innocenso R. Savonarola [Alphonsi Lasor de Varea] Universus Terrarum Orbi Scriptorum Calamo Delineatus ${ }^{25}$ (1713), pero sin compartir lámina, incluyendo solo texto bajo la imagen.

Mención especial merecen las más de ochocientas vistas de ciudades que reunió el editor Eberhard Kieser (1583-1631), rehaciendo su diseño e incorporando escenas y textos concebidos por el poeta Daniel Meisner (1585-1631). Se publicaron en Frankfurt en 1623 con el título Thesaurus Philo-Politicus (tomo 2) y en 1626 como Thesaurus sapientiae civiles $^{26}$. En 1638 se editaron en Nuremberg con el nombre Libellus novas politicus emblematicus Civitatum. También aparecieron en Nuremberg como Sciografía Cósmica entre 1637 y 1642, y se reeditaron en 1678 y en 1700 como Politica Politica.

Cada vista incluyó un título en latín, a modo de lema, y abajo una especie de moraleja -en latín y/o alemán- con textos procedentes de la sabiduría popular, de tratados morales o de obras clásicas, en relación con las escenas y personajes incorporados en primer plano. De este modo, se conformaron mensajes simbólicos con ideas antiespañolas y connotaciones negativas en el contexto de las disputas religiosas de aquel tiempo. Las dieciocho láminas andaluzas incluidas están plagiadas del Civitatis. La vista de Córdoba $\left(\mathrm{n}^{\circ} 75\right)$ (Fig. 2) fue grabada por Sebastian Furck ( $i-1655)$ e incluye un mensaje sobre la lujuria (de los españoles): Corduba Gubernat cuncta voluptas [la lujuria destrona a la virtud] y otros textos en la parte inferior ${ }^{27}$. En primer plano aparece una compleja escenografía con templetes a ambos lados, más unos diez

${ }^{24}$ Valegio, Raccolta delle più illustri... Hubo ediciones previas en las que no se ha localizado la vista de Córdoba en 1575, 1579, 1595 y 1599.

${ }_{25}$ Savonarola [Lasor a Varea], Universis terrarum orbis scriptorum, p. 299.

${ }_{26}$ Meissner, Thesaurus sapientiae civilis... $\mathrm{n}^{\circ} \mathrm{G} 75$.

${ }^{27}$ El texto viene a decir (traducción libre): Todo lo rige el placer / Córdoba en España / Necio bebe, diviértete, tras la muerte no hay placer: El Mundo cría cerdos, tragones y borrachos: Ahora la lujuria domina el Mundo, la juventud es expulsada muy lejos / Esto es el Mundo en su esplendor, que menosprecia a Dios y su palabra. 


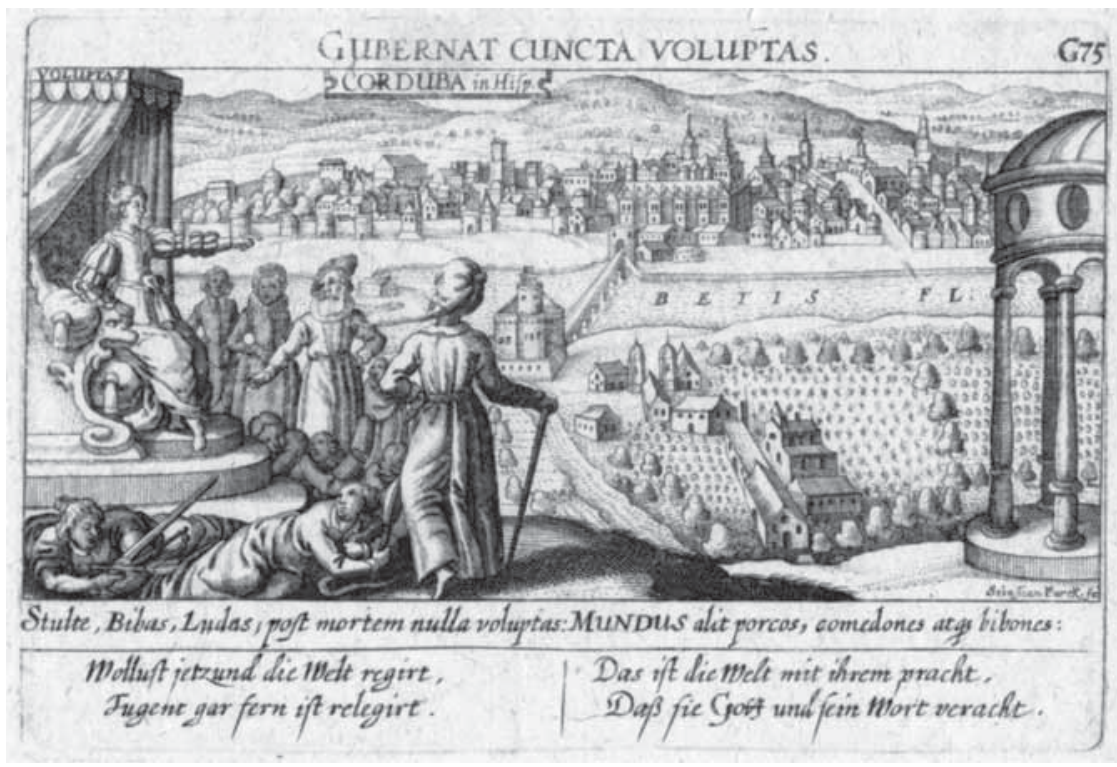

Fig. 2. Daniel Meisner / Sebastian Furck (grab.), h. 1626: Córdoba (col. particular)

personajes, y al fondo la ciudad con la Mezquita-Catedral muy simplificada.

El viajero Martín Zeiller (1589-1661) fue autor en 1656 de la obra titulada Hispaniae et Lusitaniae Itinerarium. Nova et accurata descriptione... ${ }^{28}$ que incorpora versiones bastante reducidas del Civitatis, entre ellas la vista de Córdoba, que incluyó el escudo de la Monarquía Española en el ángulo superior izquierdo.

Por otra parte, el cosmógrafo veneciano y sacerdote franciscano, Vicenzo María Coronelli (h. 1650-1718) publicó en 1706 una obra en tres volúmenes, cuyo tomo segundo se tituló Teatro della guerra, Gran Bretagna, Spagna, Portogallo ${ }^{29}$, con setenta y seis vistas españolas de las que treinta y ocho se dedicaron a Andalucía. Se realizaron dos copias distintas de la vista cordobesa del Civitatis, ambas simplificadas y toscas, con los títulos "Corduba" y "Cordova". La segunda comparte lámina con la Torre del Oro de Sevilla.

${ }^{28}$ Zeiller, Hispaniae et Lusitaniae Itinerarium... p. 314.

${ }^{29}$ Coronelli, Teatro della guerra... El tomo I se tituló Teatro della guerra, Belgio e Olanda; y tomo III Teatro della guerra. Francia. La Francia divisa in 12 prefetture. 
Otras importantes versiones del Civitatis, que incluyeron nuevas figuras o personajes, fueron publicadas por el impresor, grabador y cartógrafo flamenco Pieter van der Aa (1659-1733) (también aparece escrito como Van der A. A.) en diversas ediciones que se convertirían en las más importantes guías de la Europa del momento. En 1707 se publicó Beschirywing van Spanjen en Portugal... ${ }^{30}$, con unas ciento sesenta y seis estampas que carecen de firma. En la parte superior de la vista de Córdoba figura el texto "BESCHRYVING VAN CORDUA". La leyenda aparece abajo en francés y se repite en holandés entre el propio texto.

El mismo editor publicó dicha obra con textos en francés en 1707 (y 1715) bajo el título Les Delices de L'Espagne et du Portugal... ${ }^{31}$, en seis volúmenes en los que figura como autor Juan Álvarez de Colmenar, que quizás fue un pseudónimo. Incluye las mismas vistas pero el formato reducido del libro obligó a doblar todas las láminas. En el volumen III, Les Provinces d'Andalousie, \& de Grenada, \& de l'Ile de Cadix aparece la vista de Córdoba, que se distingue de otras ediciones por el número de página “(Pág. 404)” incluido en la esquina superior derecha.

Las planchas volvieron a usarse en otra obra de Pierre [o Pieter] van der Aa, un atlas con sesenta y seis tomos en veintinueve volúmenes que comprenden todo el mundo, publicado en la década de 1720, posiblemente hacia 1723 (y después en 1745). A España se dedicó el tomo segundo, La Galerie Agreable du Monde: Tome Second, Du Rö̈aume $D^{\prime} E_{\text {spagne }}^{32}$, con sesenta y cinco estampas de considerable tamaño (606 x $476 \mathrm{~mm}$.) que en muchos casos agrupaban cuatro ciudades. La vista de Córdoba comparte la lámina número 33 con Écija, Alcantarilla y Los Palacios.

Otro álbum de Pieter van der Aa, con ciento sesenta y siete estampas, entre ellas la vista cordobesa, se tituló Les Royaumes d'Espagne et de Portugal... sin incluir fecha, aunque se ha datado hacia $1730^{33}$.

${ }^{30} \mathrm{Aa}(\mathrm{ed})$, Beschirywing van Spanjen en Portugal...

31 Álvarez de Colmenar y Aa (ed.), Les delices de l'Espagne \& du Portugal... tomo 3, p. 404.

32 Aa (ed.), La Galerie Agreable du Monde: Tome Second, Du Rö̈aume D'Espagne, p. 33.

${ }_{33}$ Aa (ed.), Les Royaumes d'Espagne et de Portugal... (h. 1730). Fecha indicada por Palau y Dulcet, Manual de Librero Hispano-Americano... 
Además, la edición francesa de 1707 de Juan Álvarez de Colmenar se reeditó en 1741 en cuatro tomos con el título Annales d'Espagne et Portugal... ${ }^{34}$ En el segundo tomo la vista de Córdoba comparte ahora lámina con una mapa titulado "Nouvelle carte d'Andalousie et Grenade".

Finalmente, la obra de Bernardo Espinalt y García, Atlante español... (h. 1779-87) incluye una lámina plegada titulada "Vista meridional de la ciudad de Córdoba". Se trata de otra copia del Civitatis, redibujada por Juan Fernández Palomino (?-1793) ${ }^{35}$.

\section{La panorámica de Pier María Baldi (1668)}

En la biblioteca Laurenziana de Florencia se conserva una importante colección de vistas urbanas dibujadas por el arquitecto Pier María Baldi (h. 1630-1686). Éste formaba parte del cortejo de Cosme de Médicis cuando era príncipe y futuro Gran Duque de la Toscana y viajó por España en los años 1668 y 1669. Dibujó veintiuna vistas de poblaciones andaluzas que no se han publicado hasta el siglo $\mathrm{XX}^{36}$, siendo muchas su primera imagen conocida.

Visitó Córdoba en diciembre de 1668 y realizó una panorámica acuarelada con un novedoso punto de vista situado hacia el sur, junto al meandro del Guadalquivir, desplazado hacia levante respecto a las vistas de Wyngaerde y del Civitatis. Incluye en primer plano un valioso testimonio gráfico de la puerta de Baeza, desaparecida hacia 1869 y del lienzo oriental de la muralla. Al fondo aparece un paisaje esquemático en el que apenas destacan edificios, salvo la Mezquita-Catedral que sobresale en la lejanía entre el perfil urbano, en las cercanías del puente y la torre de la Calahorra.

\section{Imágenes esquemáticas en el siglo XVIII}

Otras representaciones muy distintas fueron las ilustraciones de letras capitales que adornaban, a modo de miniaturas, el inicio de páginas

34 Álvarez de Colmenar, Annales d' Espagne et de Portugal... tomo 2.

${ }_{35}$ Espinalt y García y Fernández Palomino (dib.), Atlante español... tomo XI, p. 152.

${ }^{36}$ Sánchez Rivero (edición y notas), Viaje de Cósme de Médicis... Catálogo, El Viaje a Compostela de Cosme III de Médicis, pp. 476-477. 
de algunos libros del XVIII. En un libro coral aparece una vista atribuida a Marco de Roelas en 1722: junto a la letra D se representa el crucero que cubre la traza ovalada del arquitecto Juan de Ochoa, junto al caserío del antiguo barrio de Santa María ${ }^{37}$. En el Libro de Recibimientos de Oficios y Juramentos (1744) destaca otra vista de Antonio Junguito de Guevara: junto a la letra V aparece el puente romano, la torre de la Mezquita-Catedral y lucernarios de su cubierta, todo ello desproporcionado pero con cierto interés ${ }^{38}$. Dicho libro incluye vistas esquemáticas sobre otros elementos urbanos: murallas, puertas, espadañas, Corredera, Cabildo Municipal y una ermita extramuros ${ }^{39}$.

También cabe citar algunos atractivos relieves pétreos de los siglos XVII y XVIII o representaciones muy esquemáticas localizadas en el propio monumento: en la torre-campanario, en la capilla de la Purísima, en el coro, en el cancel del Arco de las Bendiciones y en el cancel del Sagrario. También hubo pinturas murales en el muro sur, y además, relieves en plata sobre terciopelo o en latón ${ }^{40}$.

Por otra parte, una pintura de Acisclo Antonio Palomino (16551726) ubicada en la capilla de Santa Teresa de la Mezquita-Catedral, datada hacia 1712-1713, representa la conquista de Córdoba por San Fernando, incluyendo como fondo la torre de la Calahorra y el perfil o cubiertas del crucero de la Catedral ${ }^{41}$. Asimismo cabe mencionar un grabado anónimo datado hacia 1770 que ilustra de forma imaginaria el intento de asalto del rey de Granada a Córdoba en $1367^{42}$. La representación de la urbe apenas se ajusta a la realidad: en primer plano aparece el puente, vital para la defensa de la ciudad, en el que se había destruido uno de sus arcos para cerrar el paso al enemigo.

Y también cabe citar otra estampa suelta bastante esquemática, cuyo dibujo se atribuye a Miguel Verdiguier (1706-1796), grabada por Bartolomé Vázquez hacia 1781. Está protagonizada por el monumento del Triunfo del Arcángel San Rafael que el Cabildo Catedralicio encargó

37 Libro Coral Capitularium, s/n y s/f. Archivo de la Catedral de Córdoba. Cosano Moyano, Iconografia... (1999) pp. 98-99 y 523.

38 Junguito de Guevara (dib.), Libro de Recibimientos... p. 5. Nieto Cumplido, La Catedral... p. 590. Cosano Moyano, Iconografia ... pp. 101 y 524.

39 Junguito de Guevara (dib.), Libro de Recibimientos... pp. 3bis, 7bis, 11bis, 14bis, 18bis, 20, 20bis, 26. Cosano Moyano, Iconografia... pp. 100, 102-109.

${ }^{40}$ Cosano Moyano, Iconografía... pp. 291-304

${ }^{41}$ Nieto Cumplido, La Catedral... p. 373. Cosano Moyano, Iconografí... p. 543.

42 Adquirido hacia el año 2004 por el Museo de Bellas Artes de Córdoba. 
en 1765 a Verdiguier, y que se erigió a las puertas del Palacio Episcopal, junto a La Mezquita-Catedral y al puente ${ }^{43}$.

\section{El primer plano del monumento, un óleo anónimo (1741)}

En contra de lo que cabría esperar, no se han conservado dibujos ni planos de las importantes obras renacentistas iniciadas por Hernán Ruiz I en la Mezquita-Catedral ${ }^{44}$. Los primeros dibujos arquitectónicos del monumento conocidos son tres planos de Gaspar de la Peña del año 1679 , que aportan poca información sobre parte del patio y sus galerías. Reflejan propuestas de una Capilla Real de nueva planta en el "Corral de los Naranjos", que no se llegó a ejecutar por la oposición del Cabildo ${ }^{45}$.

La primera representación en planta del conjunto de la Mezquita-Catedral es un óleo anónimo, fechado en $1741^{46}$ según la propia leyenda, en la que se indica que su delineación fue realizada por encargo del obispo de Córdoba, Pedro Salazar y Góngora, que desempeñó su cargo entre 1738 y 1742. La imagen incluye a su izquierda una vista frontal de la nueva torre campanario, enmarcada por ramos de flores. En la parte derecha aparece la planta del monumento, en la que destacan los muros representados en color rojo y la vegetación que entonces existía en el patio. Abajo, una valiosa leyenda incluye cuarenta y cinco referencias sobre usos de distintas dependencias, además de los rótulos incluidos en el propio dibujo. Aunque no es un documento de gran precisión, tiene gran importancia para estudiar posteriores obras de restauración.

\section{Un dibujo esquemático en la colección Vázquez Venegas (1752)}

En los siglos XVII y XVIII fueron frecuentes los dibujos de ciudades sin escala y cuando la exactitud métrica no era algo imprescindible, la realidad se abstraía de forma intuitiva, prescindiendo de laboriosas

${ }^{43}$ Cosano Moyano, Iconografia... pp. 140-144.

${ }^{44}$ Gimena Córdoba, Forma, espacio y estructura en la transición al Renacimiento cordobés...

${ }^{45}$ Nieto Cumplido y Luca de Tena, La Mezquita... $\mathrm{n}^{\mathrm{o}} 1,2$ y 3

${ }^{46}$ Nieto Cumplido y Luca de Tena, La Mezquita... no 4. 
medidas. Para conseguir una mayor expresividad, a veces se combinaba el dibujo en planta con escuetas vistas en perspectiva de ciertos edificios, para destacarlos y facilitar su identificación visual. De este modo se acometió un singular dibujo anónimo de la ciudad de Córdoba datado en 1752, que forma parte de la colección documental Vázquez Venegas del Archivo de la Catedral de Córdoba ${ }^{47}$.

Se trata de un dibujo a lápiz, con rótulos en tinta, que pretendía ubicar en la ciudad los edificios religiosos aludidos en el documento literario del que forma parte. La representación es muy esquemática, pero ordenada y lógica, reflejando lo esencial en la estructura urbana. Se concibió como una planta que incluye el puente y el río en primer plano más el recinto amurallado, pero no el caserío. Además, se insertaron imágenes muy esquemáticas de las iglesias, con especial atención a las torres, a veces desplazadas o giradas para favorecer su mejor identificación. Entre ellas aparece una viñeta de la Iglesia Mayor, muy desproporcionada. No obstante, resulta elocuente la representación del edificio islámico como un gran basamento en el que sobresale el edificio catedralicio, cuyas obras estaban muy avanzadas.

\section{Los primeros planos científicos de los Académicos (1767-1804).}

Tras la fundación en 1752 de la Real Academia de Bellas Artes de San Fernando de Madrid, se promovió el estudio y la documentación de piezas clave para la historia de la arquitectura en España, especialmente de su arquitectura árabe. Aunque el estado de conservación de monumentos como la Alhambra era muy preocupante, no eran dibujos destinados a realizar obras inmediatas. Se pretendía poner en valor y difundir la imagen de importantes edificios que no contaban con dibujos publicados y acometer un inventario artístico-arquitectónico que fue una gran novedad para su época, con la participación de arquitectos, grabadores y filólogos de primera línea. Frente a posteriores imágenes del XIX, más atentas a las sensaciones que provocaba la arquitectura islámica, se aportó una información objetiva y global sobre su estado real en aquel momento.

${ }^{47}$ Existe copia de la época de dicho dibujo en el Archivo Histórico Nacional (Legajo 3018, sig. Estado-795). García Ortega y Gámiz Gordo, "La ciudad de Córdoba en su primer plano...", pp. 23-40. 
Los pormenores sobre esta iniciativa se analizan en un libro de Delfín Rodríguez y en un catálogo editado por Antonio Almagro que incluye los originales conservados en la Real Academia de San Fernando $^{48}$. En 1763 hubo un primer encargo al pintor Diego Sánchez Sarabia (1704-1779) y entre 1766 y 1767 el trabajo fue acometido por un equipo de la propia Academia, encabezado por José de Hermosilla (1715-1776) junto a los jóvenes Juan de Villanueva (1739-1811) y Juan Pedro Arnal (1735-1805). Tras los dibujos realizados en Granada, los primeros planos a escala de la Mezquita-Catedral se acometieron en marzo de 1767. Se siguieron criterios considerados como científicos, usando la geometría como fundamento de la disciplina gráfica para comprender la composición y distribución de la arquitectura, dibujada con rigor y sensibilidad.

Ello dio lugar a la publicación titulada Las Antigüedades Árabes de España, en dos tomos aparecidos en 1787 y 1804, con grabados realizados por destacados especialistas españoles. La primera parte incluye treinta láminas: veinte y cuatro de Granada y seis de Córdoba. La segunda parte, con detalles de inscripciones y traducciones de Pablo Lozano, veintinueve láminas, cuatro de ellas sobre Córdoba (láminas XXVI a XXIX).

Los más interesantes son una planta (Fig. 3) y dos secciones (Fig. 4) de la Mezquita-Catedral. Según ha constatado Antonio Almagro, la planta es bastante precisa, tanto métricamente como en la interpretación de la estructura y organización espacial ${ }^{49}$, aunque se evitó incluir retablos y altares, sustituidos por pequeñas cruces y un número referido a la leyenda situada en el margen. Se dibujaron con distinta intensidad los muros de época islámica y cristiana, de forma bastante correcta, aportando por primera vez una interpretación arqueológica del monumento. Además, se realizó una hipótesis de la planta en tiempos islámicos, sin añadidos cristianos. Una de las secciones se planteó por el crucero renacentista, mostrando de forma muy elocuente su contraste con la Mezquita; mientras que la otra comprendía la nave central del oratorio musulmán.

48 Rodríguez Ruiz, La memoria frágil... Almagro Gorbea, El legado de al-Ándalus...

49 Almagro Gorbea, "Las antigüedades árabes en la Real Academia ...", El legado de al-Ándalus... pp. 13-29. 


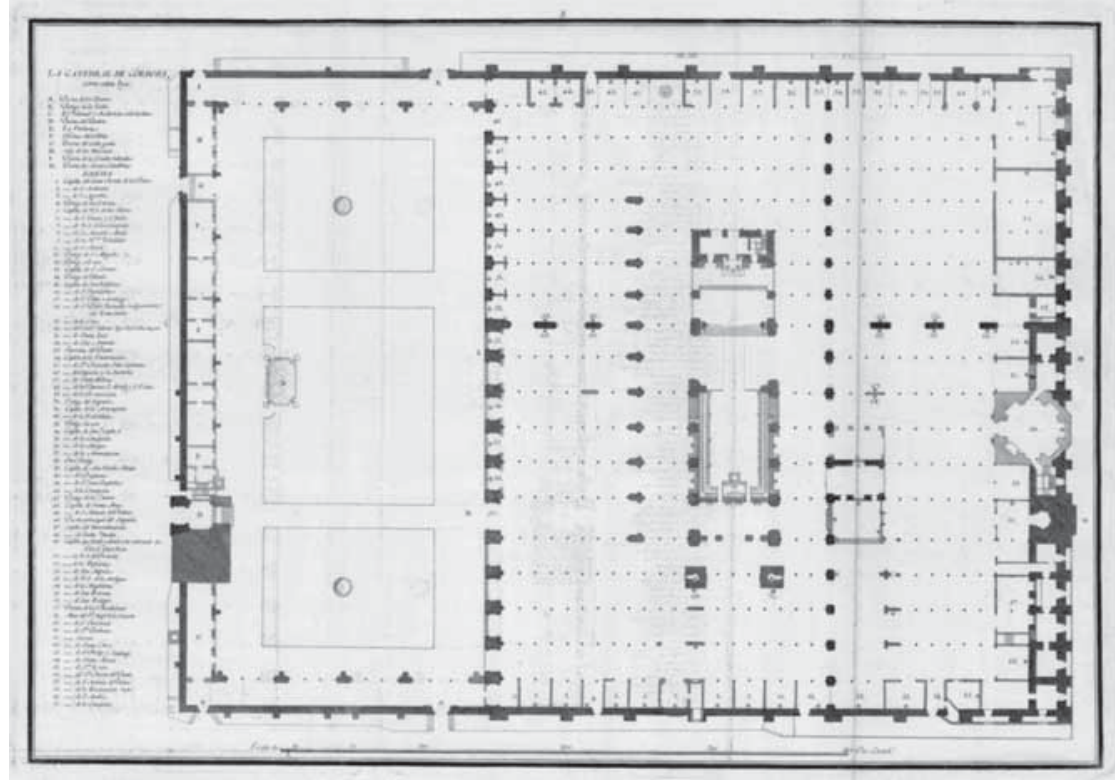

Fig. 3. Real Academia de Bellas Artes de San Fernando de Madrid (ed.) 1787: Planta de la Mezquita-Catedral de Córdoba (col. particular)

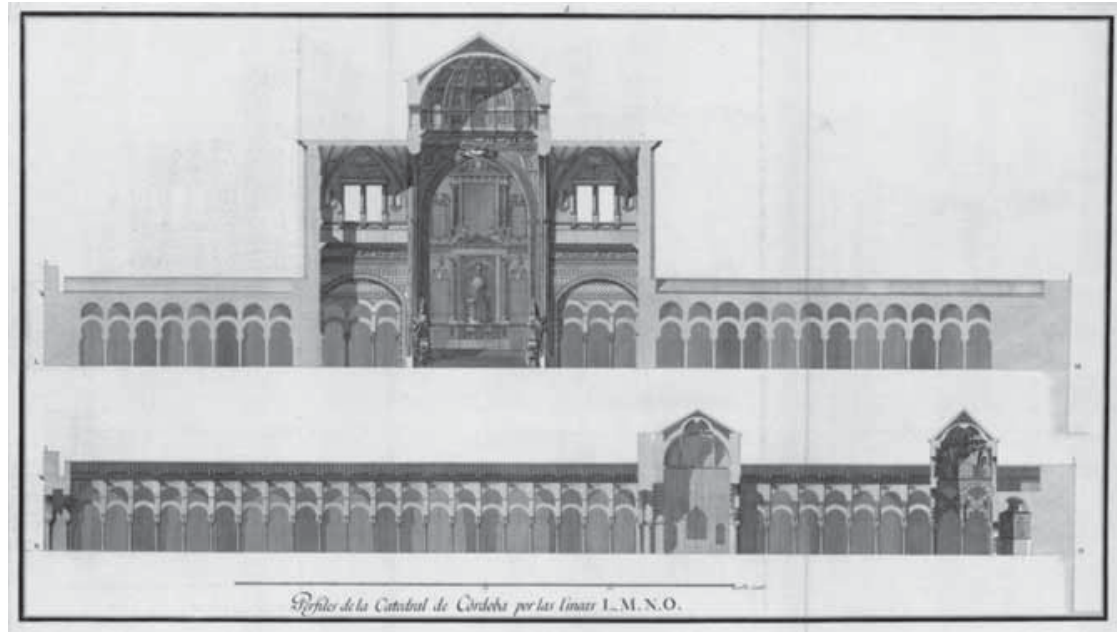

Fig. 4. Real Academia de Bellas Artes de San Fernando de Madrid (ed.), 1787: Secciones de la Mezquita-Catedral de Córdoba (col. particular) 
Además de una lámina con capiteles, realizaron dos vistas urbanas de menor calidad, publicadas como portadilla de presentación de las otras láminas. Una incluye la torre de la Calahorra y el puente dibujado de forma muy simplista, con sólo trece de sus diecisiete arcos, apareciendo al fondo dos de las fachadas de la Mezquita-Catedral que deberían quedar ocultas por el caserío circundante, en un entorno urbano deformado y poco creíble. La otra vista comprende dos fachadas del monumento, sobre las que emerge la torre-campanario y el crucero, en un entorno idealizado, a modo de extraña explanada.

La planta general de la Mezquita-Catedral y la vista con el puente fueron copiadas en el libro de Antonio Ponz, Viaje de España (17721794) en sus tomos XVI y XVII ${ }^{50}$. También deben destacarse los plagios publicados por Jean François Bourgoing (1745-1811) ministro plenipotenciario de la Corte de Francia en Madrid, autor en 1788 de la obra titulada Nouveau Voyage en Espagne, ou Tableau de l'État Actuel de Cette Monarchie... objeto de abundantes reediciones en varios tomos, con títulos cambiantes y variadas modificaciones: Tableau de l'Espagne Moderne en 1797, 1807 y 1808, Atlas pour servir au tableau de l'Espagne moderne en 1803, 1807 y 1808, más otras ediciones en inglés en 1789, 1803, 1808 y 1809, y en alemán en 1789-90². En las páginas finales del volumen 3 de las ediciones aparecidas a partir de $1807^{52}$ se añadieron cuatro láminas de la Mezquita-Catedral copiadas de los académicos con escasa calidad gráfica: plantas y secciones, más la vista exterior con las fachadas, en la que se modificaron los primeros planos. Además, los levantamientos de los Académicos fueron cuidadosamente copiados en la obra de Alexandre Laborde y también en la de James Murphy, después comentadas.

\section{Las vistas de Henry Swinburne (1775)}

Durante el siglo XVIII fueron frecuentes los viajes como parte del proceso educativo de jóvenes europeos de clases altas, especialmente por Francia e Italia. La literatura de viajes adquirió una considerable

${ }^{50}$ Ponz y Piquer, Viaje de España... tomos XVI y XVII.

${ }^{51}$ Foulche Delbosch, Bibliographie des voyages... pp. 136-144, $\mathrm{n}^{\mathrm{o}} 189$.

52 Bourgoing, Tableau de L'Espagne Moderne... (1807) tomo III. 


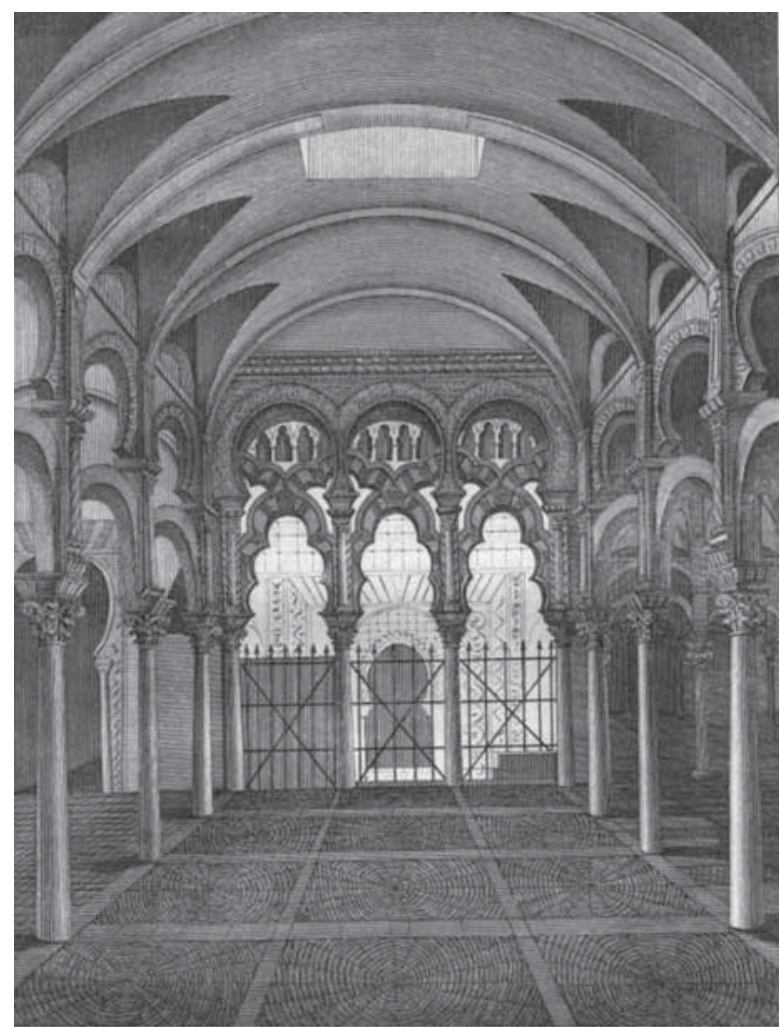

Fig. 5. Henry Swinburne (dib.) / F. Giomignani (grab.), 1779: Nave principal hacia el Mihrab (col. particular)

importancia, aunque pocos viajeros se aventuraron a recorrer España hasta finales de dicho siglo, cuando se despertó el interés por visitar monumentos como la Alhambra o la Mezquita-Catedral de Córdoba. Desde entonces nuestro país fue recorrido por muchos viajeros, a los que se ha llamado "curiosos impertinentes" 53 , que buscaban lugares cargados de historia, emociones e ideales de belleza. La publicación de sus dibujos y textos se convertirían en verdaderos tópicos sobre nuestro pasado islámico, cobrando protagonismo las impresiones personales de sus autores, con una voluntad "emocionalista" muy distinta a las tradiciones estéticas clasicistas dominantes hasta entonces.

53 Robertson, Los curiosos impertinentes... 
Entre ellos ${ }^{54}$, cabe destacar a Henry Swinburne (1743-1803) que en 1779 publicó su libro Travels throught Spain in the years 1775 and 1776... 55 , un clásico de los viajes por España para el público británico y europeo. Se reeditó en 1795 y en 1787 apareció una edición francesa sin láminas, Voyage de Henri Swinburne en Espagne en 1775 et 1776. En 1806 se publicó con distintas láminas y diferente título, Picturesque tours throught Spain ${ }^{56}$, volviendo a editarse en 1808, 1810 y 1823.

Swinburne realizó una vista desde el meandro del Guadalquivir con la Mezquita-Catedral al fondo, desde una ubicación cercana a la vista de Baldi. También dibujó una de las portadas exteriores y la primera perspectiva interior conocida del monumento, en su nave principal hacia el Mihrab (Fig. 5), todas ellas toscamente grabadas. Además, el libro incluyó una planta esquemática del monumento en tiempos islámicos, sin inserciones cristianas, junto a una sección-alzado del sistema de arquerías y otros detalles.

\section{El plano de la ciudad de Karwinsky y Rillo (1811)}

El primer plano a escala de la ciudad de Córdoba y sus alrededores fue realizado en 1811, durante el periodo de ocupación francesa, por el barón de Karwinsky (1780-1855) y Joaquín Rillo (h. 1782- ?) ${ }^{57}$. Se realizó usando metodologías de levantamientos topográficos de minas en galería o "geometría subterránea" que no se conocían en España, según reciente tesis doctoral (2017) que ha aportado una excelente restitución digital del plano original ${ }^{58}$. Es propiedad del Ayuntamiento de Córdoba, tiene un gran tamaño (1751 x $2215 \mathrm{~mm}$.) y un estado de conservación delicado que ha impedido su adecuada reproducción, por lo que se le suele conocer por una copia reducida e incompleta que en 1923 realizó Miguel Ángel Ortí Belmonte, publicada en $1930^{59}$.

${ }^{54}$ López Ontiveros, La imagen geográfica de Córdoba en la literatura viajera...

55 Swinburne, Travels throught Spain in the years 1775 and 1776.

${ }^{56}$ Swinburne, Picturesque tour through Spain...

57 Torres Márquez y Naranjo Ramírez, "El casco histórico de Córdoba y el primer plano...", pp. 129-151.

${ }^{58}$ Cea Garcia, Análisis cartográfico y representativo del plano urbano de Córdoba de $1811 \ldots$

59 Ortí Belmonte, Córdoba durante la guerra de la independencia (1808-1813). 
Fue redactado para el control civil de la ciudad, con una gran precisión y un nivel de detalle más propio de planos catastrales que militares, con una escala aproximada de 1:1210. Se orientó con el sur situado arriba e incluye una valiosa y poco conocida nomenclatura de calles. La Mezquita-Catedral quedó representada por la línea que envuelve su contorno externo, indicándose el espacio del patio de los Naranjos.

En 1851 José María Montis y Fernández $(1838-1887)^{60}$ publicó un plano de Córdoba de menores dimensiones $(70$ x $56 \mathrm{~cm}$.), con escala de 500 varas castellanas y una extensa leyenda, en la que se dice que era una réplica reducida y reformada del plano de Karwinsky y Rillo de $1811^{61}$. Incluye diferencias gráficas, como el rayado diagonal usado para resaltar las manzanas, o actualizaciones en algunas zonas.

\section{La primera colección de vistas de Alexandre Laborde (1812)}

La ocupación del territorio español por los ejércitos francés e inglés durante la guerra de la Independencia facilitó el conocimiento de paisajes y lugares hasta entonces poco conocidos en Europa, a través de nuevas técnicas de estampación que contribuyeron a visualizar el monumento cordobés de una forma novedosa y atractiva.

Louis Joseph Alexandre de Laborde (1773-1842) visitó Córdoba hacia el año 1800, cuando recorría España dirigiendo a un equipo de artistas para dibujar destacados lugares y monumentos arquitectónicos. Dicho viaje dio lugar a unos trescientos cincuenta grabados publicados en el $\mathrm{Vo}$ yage pittoresque et historique de l'Espagne, con cuatro tomos entre 1806 y 1820. La obra tuvo una doble concepción gráfica y literaria, sin una clara frontera entre las disciplinas del artista-dibujante, del historiador y del científico. El tomo II (1812) comprende setenta y ocho grabados, los veintiún primeros dedicados a Córdoba y el resto a Granada. Incluye la primera colección de vistas y planos de la Mezquita-Catedral ${ }^{62}$.

${ }^{60}$ Cea Garcia, Análisis cartográfico y representativo... pp. 206-208.

${ }^{61}$ En el propio plano dice: "El plano de esta ciudad fue formado en 1811 por el ingeniero de Minas Barón de Karwinsky y el de puentes $D^{\circ}$ Joaquín Rillo. Reducido y reformado en el de 1851 por $D^{\circ}$ José María Montis y Fernández, comprobado por el Arquitecto $D^{\circ}$ Pedro Nolasco Meléndez y aprobado por la Real Academia de San Fernando".

${ }^{62}$ Gámiz Gordo y García Ortega "La primera colección de vistas de la Mezquita...", pp. 105-124. 


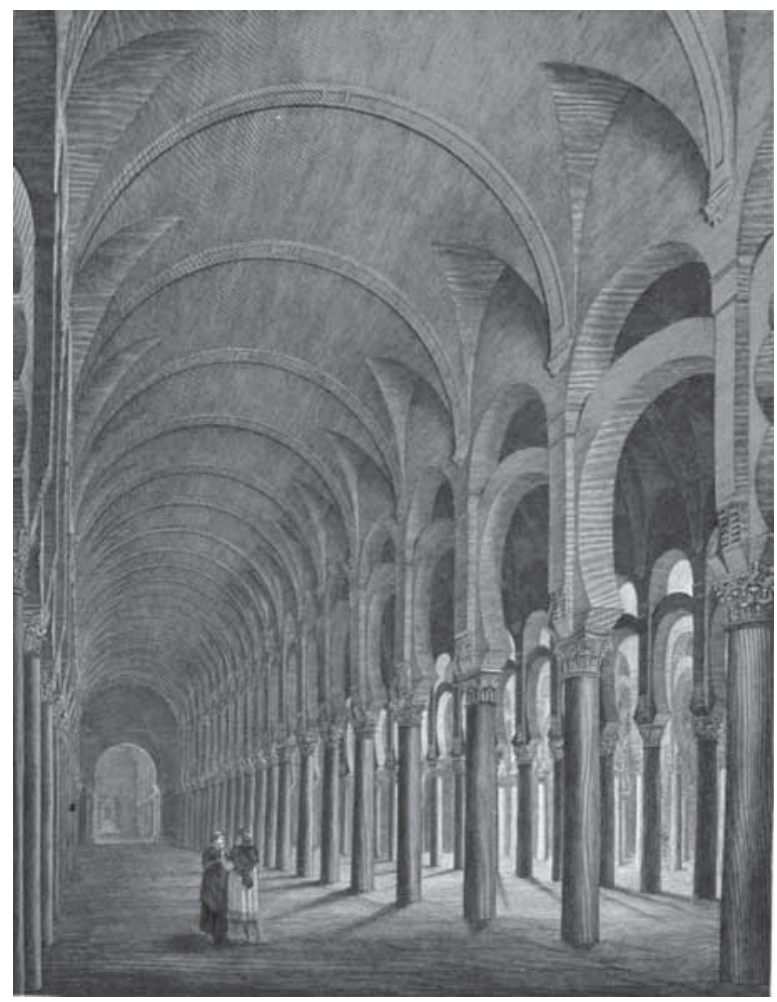

Fig. 6. Alexandre Laborde (dir.) / Six [o ¿Ligier?] (dib.) / Smith (grab.), 1812: Interior de la Mezquita de Córdoba (col. particular)

Entre los artistas que participaron cabe destacar a Jean Lubin Vauzelle (1776-1837), reconocido pintor de paisajes y arquitecturas ${ }^{63}$, y al menos conocido arquitecto François Ligier, autores cada uno de ocho láminas sobre Córdoba. La obra incluye dos vistas urbanas de la Mezquita-Catedral, más otras sobre su patio, interiores (Fig. 6), planos y detalles. Aunque gran parte de la planimetría fue cuidadosamente copiada de los Académicos, se aportaron nuevos planos con detalles propios.

${ }^{63}$ Quesada, Pintores españoles y extranjeros en Andalucía, p. 73. En dicho libro se reproduce un original del interior de la Mezquita de Vauzelle. Se le atribuye otra vista interior subastada en Drouot Richelieu, Salle 5, Dessins et Tableaux Anciens, París, 15/10/2013. 
En el Museo Nacional d'Art de Catalunya se conservan seis originales dibujados a línea ${ }^{64}$, cuatro de ellos de Ligier: dos del patio y dos del crucero renacentista que no se grabaron, más un interior y un capitel. Y en la Bibliothèque de l'Institut National d'Histoire de l'Art de París (col. Jacques Doucet) hay dos originales sombreados, uno de Ligier con la puerta del Perdón y otro interior con naves y arquerías.

A pesar de la variedad de temas y del amplio equipo de dibujantes, la obra mantuvo una gran unidad y rigor, ya que se usaría cámara oscura para encajar y proporcionar las vistas de forma objetiva. Por tanto, se trata de imágenes ajustadas a la realidad, con fiable información. Los puntos de vista fueron novedosos y los encuadres elegidos aportaron visiones atractivas. Sin llegar a ser obras maestras, la colección de vistas se dibujó con gran rigor y sensibilidad, invitando a su contemplación y disfrute.

Tres de las láminas fueron plagiadas por G. Bussi e incluidas en el libro de Jules Ferrario, Le Costume, Ancien et Moderne (1825) ${ }^{65}$ : una vista exterior de la Mezquita, otra interior y detalles de ornamentos.

\section{Las antiguedades árabes de James C. Murphy (1802-1813)}

El arquitecto irlandés James Cavanah Murphy (1750-1814) fue autor de una famosa obra titulada The Arabian Antiquities of Spain (Londres, 1813) dedicada en su mayor parte a la Alhambra y también a la Mezquita-Catedral, tras las estancias del autor en Granada y Córdoba hacia 1802-1807. Algunas láminas incluyen detalles que no se ajustaron a la realidad, lo que motivó duras críticas por parte de Richard Ford, que lo calificó como libro hinchado de malas copias de los Académicos ${ }^{66}$. Sin embargo, otras ofrecen inéditos puntos de vista y detalles de interés. Entre las diez láminas sobre Córdoba hay dos vistas exteriores (Fig. 7), una del patio, una interior, dos plantas similares a los Académicos, un alzado parcial del patio y otro del Mihrab, más dos sobre inscripciones. borde.

${ }^{64}$ Casanovas i Miró y Quilez i Corella (dir.), El viatge a Espanya d'Alexandre de La-

${ }_{65}$ Ferrario, Le Costume, Ancien et Moderne.

${ }^{66}$ Ford, Hand-book for Travellers in Spain. 


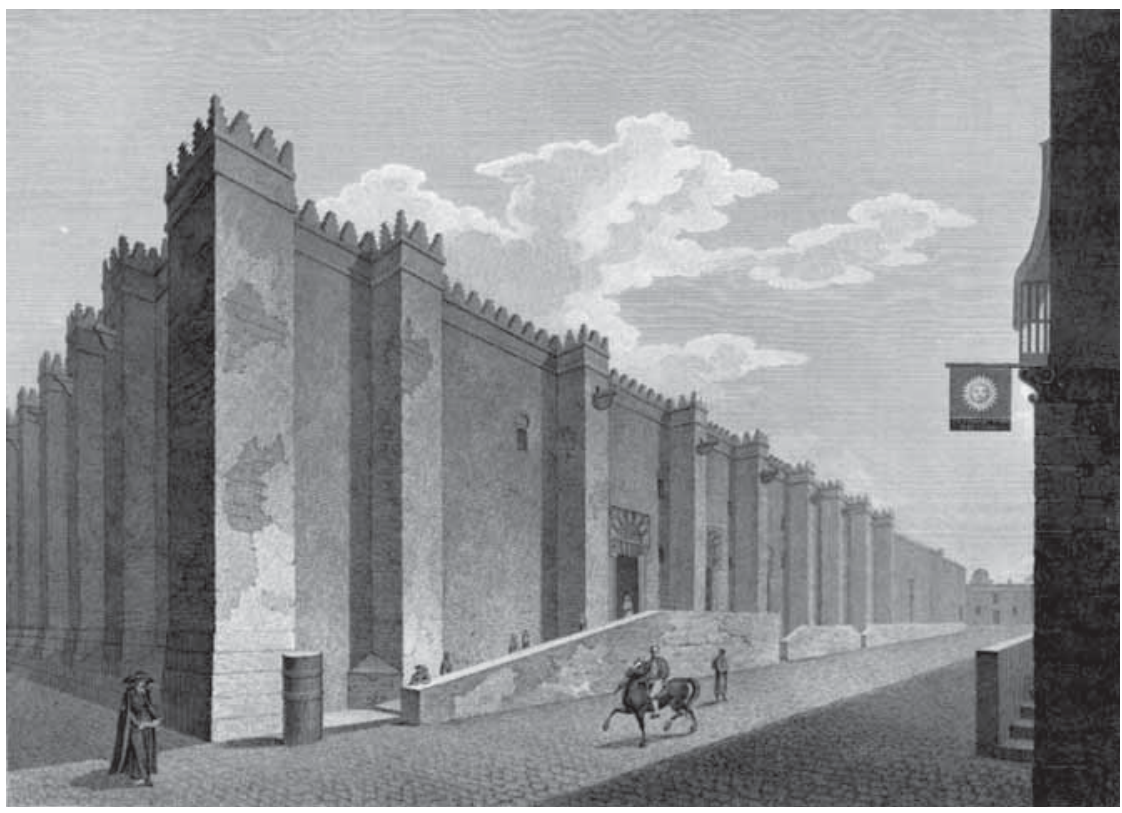

Fig. 7. Murphy (dib.) / Roffe (grab.), 1813: Exterior de la Mezquita-Catedral (col. particular)

\section{Bacler d'Able (h. 1820)}

El general Louis Albert Bacler d'Albe (1761-1824) fue un importante militar durante la guerra napoleónica, un experto en cartografía que desarrolló una singular actividad como pintor. Los dibujos realizados con motivo de sus campañas militares se publicaron en un libro titulado Souvenirs pittoresques du general Bacler d'Albe (h. 1820), editado por Engelmann, que introdujo en París las más avanzadas técnicas litográficas del momento. El segundo volumen de la serie, dedicado a España, contiene láminas que no reproducen temas militares, sino paisajes, monumentos y costumbres españolas, en muchos casos con gran parecido a las de Laborde. Incluye dos delicadas vistas del patio de la Mezquita-Catedral, con originales puntos de vista. 


\section{El baron Taylor (1826-1832)}

El barón Isidore Justin Severin Taylor (1789-1879), militar de profesión, fue también dibujante aficionado, literato y arqueólogo ${ }^{67}$. Visitó España en 1820 y en 1823 como parte del contingente armado francés. En 1826 inició en París la publicación por fascículos de su Voyage pittoresque en Espagne, et Portugal, et sur la cote d'Afrique, de Tanger a Tetouan, que se completó en 1832 , y se reeditó en $1860^{68}$. Incluía ciento sesenta y cinco estampas grabadas a partir de dibujos propios. Después de la obra Laborde, fue la publicación francesa de aquel tiempo con mayor número de vistas sobre España.

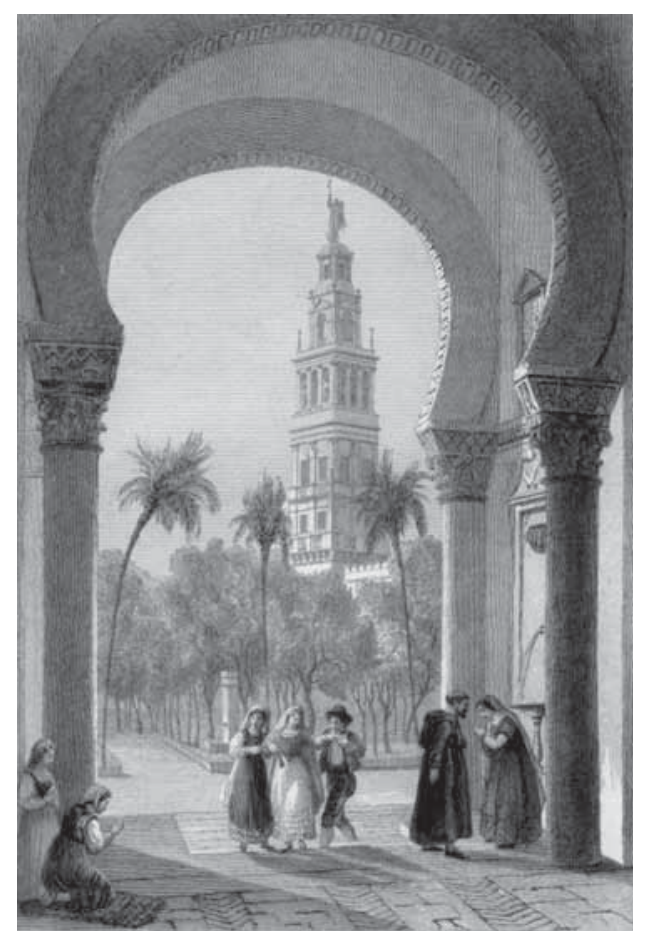

Fig. 8. Taylor (dib.) / Goodall (grab.), h. 1826-32:

Entrada al patio de la Mezquita-Catedral (col. particular)

${ }^{67}$ El barón Taylor fue autor de los Voyages pittoresques et romantiques dans l'ancienne France (publicados en fascículos desde 1819 a 1863).

${ }^{68}$ Foulche Delbosch, Bibliographie des voyages... p. 191, n³01. Catálogo (1981) p. 55. 
Según el propio Taylor, se pretendía ofrecer el álbum de un viajero que dibuja un monumento, un paisaje o una escena pintoresca sobre la cara de sus hojas y toma a la vuelta algunas notas. Así, compaginando dibujos y textos, trataría de valorar el estado ruinoso que amenazaba a gran parte del patrimonio arquitectónico español. Según algunos autores su obra fue decisiva para consolidar la imagen de España como un nuevo "destino turístico" en el contexto europeo del momento ${ }^{69}$. Entre las vistas andaluzas de Taylor, algunas bastante desproporcionadas, hay dieciséis sobre Córdoba, nueve de ellas sobre la Mezquita-Catedral: tres sobre fachadas y patio de los Naranjos (Fig. 8), más seis de interiores.

\section{Richard Ford y Harriet Ford (1831)}

El británico Richard Ford (1796-1858) llegó a Sevilla en 1830 y viajó por nuestro país durante tres años. Es bastante conocido por su famoso Manual de viajeros publicado en $1845^{70}$ con distintas reediciones que le dieron gran reputación como hispanista. Además de erudito y curioso, fue un prolífico dibujante que realizó cerca de cuatrocientas vistas en su periplo por España, en gran parte inéditas hasta una reciente exposición $^{71}$. No era un dibujante profesional, pero realizaba sus dibujos con cierta rapidez, sin pretensión de publicarlos, para conservar la memoria de los lugares visitados -pues entonces no existía la fotografía- con proporciones bastante fieles a la realidad.

El caso de Ford resulta de especial interés por su doble condición de escritor y dibujante; sus dibujos y textos se complementan y documentan una amplia diversidad de temas. Realizó muchas más vistas que otros viajeros en las ciudades en las que residió, unos noventa en Sevilla y cerca de setenta en Granada; a los que hay que sumar otros de variados enclaves andaluces. En su breve estancia de tres días en Córdoba acometió dos vistas urbanas de la Mezquita-Catedral, una con el puente romano en primer plano y otra desde el meandro del Guadalquivir, más dos bocetos inéditos de la muralla, conservados por la fa-

${ }^{69}$ Luxenberg, Secrets and Glory. Baron Taylor and his Voyage Pittoresque en Espagne.

${ }^{70}$ Ford, Hand-book for Travellers in Spain.

${ }^{71}$ Barberán, Gámiz y Robertson, Richard Ford. Viajes por España (1830-33). 
milia Ford, que también cuenta con un original del interior de la Mezquita muy distinto a los otros. Éste se atribuye a su esposa Harriet Ford, que se basaría en un dibujo de John Frederick Lewis realizado en Córdoba en noviembre de 1832, justo antes de alojarse en casa de los Ford en Sevilla, donde Harriet copió algunos de sus dibujos ${ }^{72}$.

\section{John Frederick Lewis (1832-36)}

El pintor John Frederick Lewis (1804-1876), cuyos originales se encuentran hoy en museos de todo el mundo, realizó bellísimas vistas de la Alhambra hacia 1832-1833, publicadas en 1835 como litografías, bajo el título Sketches and Drawings of the Alhambra. Además, en

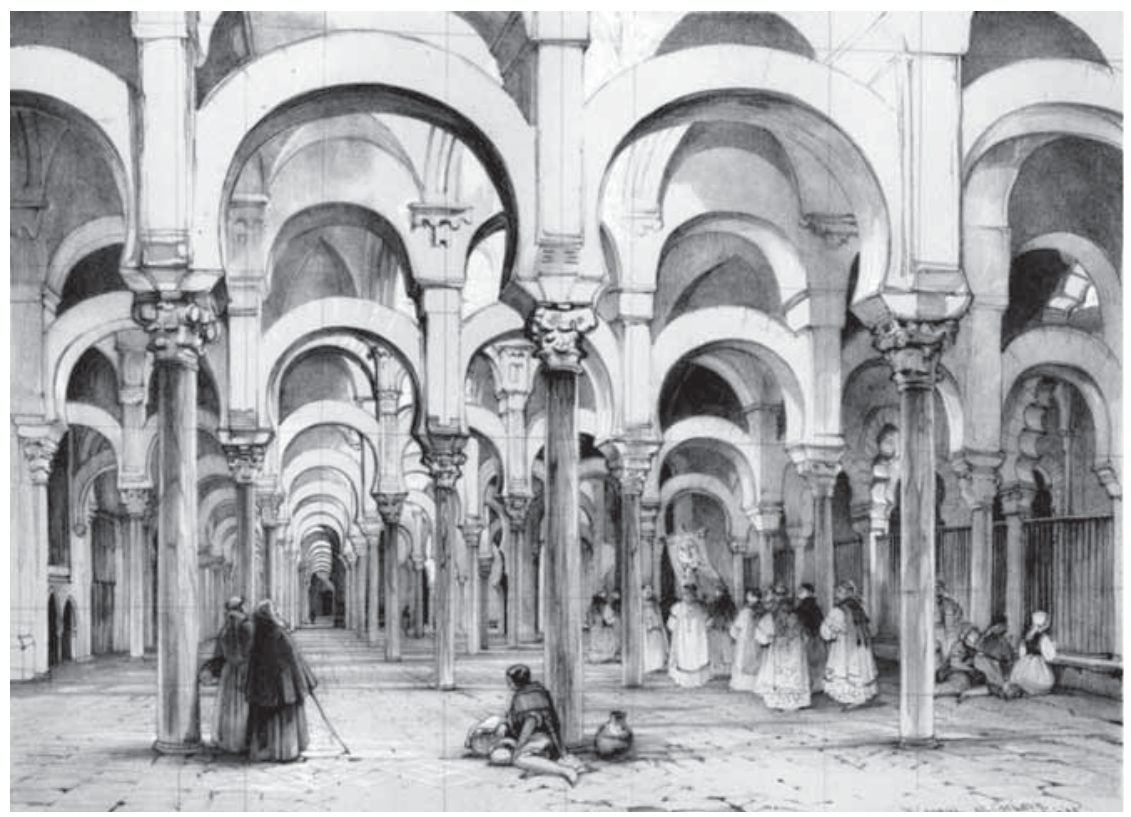

Fig 9. John Frederick Lewis (dib./ lit.), 1835: Interior de la Mezquita-Catedral (col. particular)

${ }^{72}$ Robertson, Richard Ford 1796-1858... pp. 121-122. Gámiz Gordo "Los dibujos originales de los palacios de la Alhambra de J. F. Lewis (h. 1832-33)", pp. 76-87. Gámiz Gordo y García Ortega, "Dibujos de Richard Ford en Córdoba (1831)”, pp. 143-158. 
1836 publicó otra obra similar, Sketches of Spain and Spanish Character, con tipos populares, diversas vistas de ciudades y dos láminas del interior de la Mezquita-Catedral. Una es muy similar al citado dibujo de Harriet Ford (Fig. 9) y la otra se basó en un dibujo original titulado "Misa en una capilla mora de la catedral de Córdoba" "73 con diversos personajes, entre ellos Harriet Ford vestida de mantilla ${ }^{74}$.

\section{Philibert Girault de Prangey (1832-1839)}

El arquitecto y dibujante francés Philibert Girault de Prangey (18041893) visitó Granada y Córdoba hacia 1832-33 con un equipo de dibujantes profesionales que supieron aunar en sus vistas rigor, precisión y gran expresividad. Su publicación titulada Souvenirs de Grenade et de l'Alhambra (1836) fue reeditada añadiendo imágenes de Córdoba y Sevilla con el título Monuments Arabes et moresques de Cordoue, Sevilla et Grenade (1836-1839). Incluye dos vistas urbanas cordobesas: una con el puente romano en primer plano y otra con una portada exterior de la Mezquita-Catedral (Fig. 10). Además, ocho láminas se dedicaron a interiores: cuatro perspectivas más detalles ornamentales. Algunas fueron plagiadas en la obra de Francisco Javier Parcerisa después citada.

En su posterior obra titulada Essai sur l'Architecture des Arabes et des Mores, en Espagne, et Sicilie et en Barbarie (1841) se dedica una lámina a detalles arquitectónicos, delineada por el propio autor y otra sección-perspectiva al entorno del Mihrab, dibujada por Chapuy, entre otros detalles.

Además, Girault de Prangey aparece -entre otros muchos autoresen una importante obra dirigida por Jules Gailhabaud, con diversas ediciones, una de ellas en español, Monumentos antiguos y modernos... (1845), que incluye quince páginas de texto sobre la Mezquita de Córdoba, más seis láminas cuidadosamente dibujadas, basadas en las ya antes publicadas por Prangey y otros autores.

${ }^{73}$ Quesada, Pintores españoles y extranjeros, p. 78.

${ }^{74}$ Cabe citar aquí a George Vivian (1834-38) autor de dos publicaciones con litografías parecidas a las de Lewis. Una, Spanish Scenery (1838) incluye tres bellas vistas cordobesas sin la Mezquita-Catedral. 


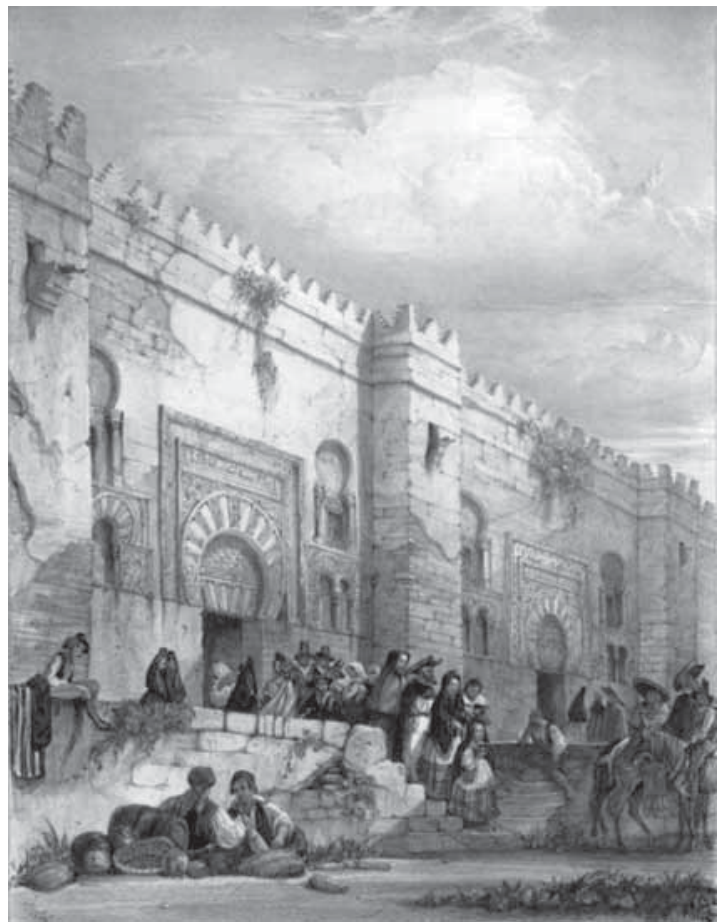

Fig. 10. Philibert Girault de Prangey (dib.) / Wyld (lit.), 1836-1839:

Portada exterior de la Mezquita-Catedral (col. particular)

\section{Wilhelm Gail (h. 1832-1837)}

Wilhelm Gail (1804-1890) ${ }^{75}$ fue un importante pintor alemán que viajó por España hacia 1832-1833 y publicó el libro Erinnerungen aus Spanien. Nach der Natur... con distintas ediciones entre 1835 y $1837^{76}$. Entre diversas vistas de Granada o Sevilla, escenas de bandoleros y corridas de toros, la lámina $\mathrm{n}^{\mathrm{o}} 12$ incluye personajes junto a una portada exterior de la Mezquita-Catedral. Además hay dos bellas obras posteriores de dicho pintor con el interior de la Mezquita: una vista hacia el

${ }^{75}$ Gebauer, Spanien Reiseland Deutscher... pp. 35-50.

${ }^{76}$ Gail, Erinnerungen aus Spanien... (1837). La fecha de 1837 se ha tomado de un ejemplar cuyo editor fue "Cotta" (Munich). Palau y Dulcet, Manual de Librero HispanoAmericano, $\mathrm{n}^{\circ} 96533$. 
Mihrab con acuarela y tinta ${ }^{77}$, y un óleo de la Capilla Real fechado y firmado en $1879^{78}$.

\section{David Roberts (1833-37)}

El pintor escocés David Roberts (1796-1864) recorrió España entre 1832 y 1833 haciendo incontables dibujos y acuarelas hoy dispersas en importantes museos y colecciones de todo el mundo. Unas setenta fueron publicadas con gran éxito entre 1835 y 1838 como grabados al acero (más pequeñas viñetas) ${ }^{79}$. En 1837 publicó, también con gran éxito, otras veintiséis litografías sobre España ${ }^{80}$. En Andalucía se ha estimado que realizó unas doscientas cincuenta vistas ${ }^{81}$.

A su vuelta a Inglaterra Roberts manipuló sus vistas del natural para satisfacer a sus clientes en pinturas al óleo; y por otra parte sus escenas fueron alteradas por grabadores y litógrafos. Por todo ello existen ciertos tópicos que le califican como creador de escenas de poca verosimilitud. Sin embargo, al analizar sus dibujos originales realizados in situ se constata su gran precisión, belleza y valor documental.

Roberts llegaría a Córdoba desde Madrid en enero de 1833 y permaneció unas tres semanas en la ciudad. Su gran interés por la Mezquita-Catedral, quedó reflejado en originales, litografías, grabados y viñetas seguidamente reseñados ${ }^{82}$. Una de las más bellas imágenes paisajísticas de la ciudad cordobesa a lo largo de su historia gráfica es la litografía de Roberts que comprende la zona monumental y la Mezquita-Catedral, desde la orilla opuesta del Guadalquivir (Fig. 11). Otra vista desde la misma orilla, al otro lado del puente, fue grabada en 1845 , con mayor protagonismo del monumento, que también quedó plasmado en un grabado y en una rara litografía con el punto de vista situado hacia el oeste, cerca del meandro del río.

Sobre el interior de la Mezquita-Catedral cabe destacar una acuarela con el retablo barroco que existió en la capilla de Villaviciosa (Fig. 12),

77 Gebauer, Spanien Reiseland Deutscher... p. 45. Subastada en Dorotheum (Viena) 5-03-2009, lote 248.

78 Subastada en Hampel (Fine Arts Auctions, Munich) 8-12-2007, lote 1588.

79 Roberts (dib.) y Roscoe (texto), The tourist in Spain, 4 tomos.

${ }^{80}$ Roberts, Picturesque sketches in Spain taken during the years 1832-1833.

81 Gámiz Gordo, "Las vistas de España del viajero David Roberts...”, pp. 54-65.

${ }^{82}$ Gámiz Gordo y García Ortega, “David Roberts en Córdoba...”, pp. 367-386. 


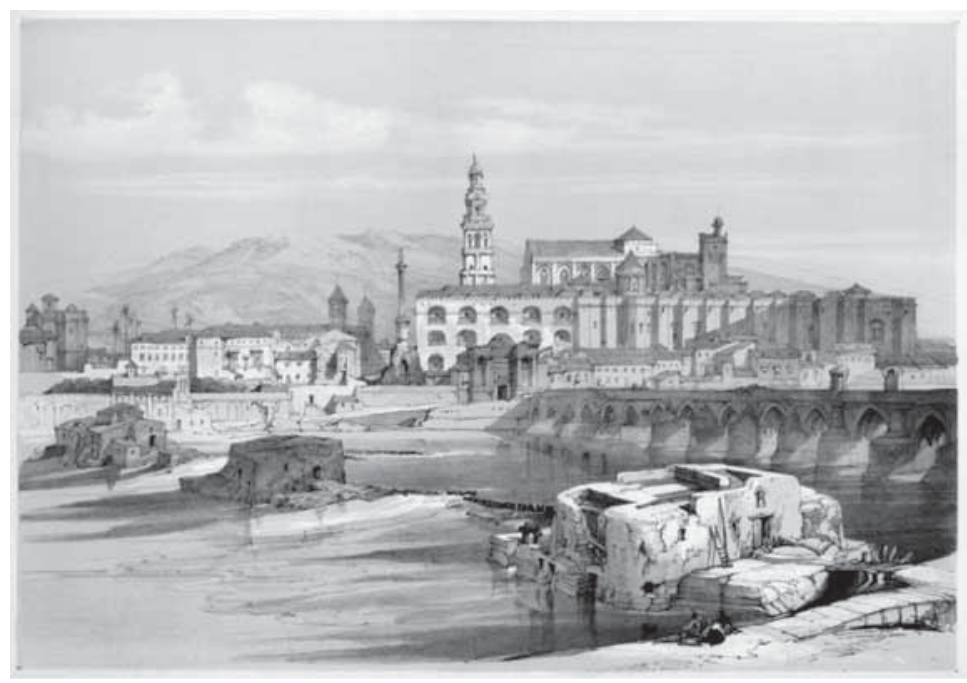

Fig. 11. David Roberts (dib.) / T. S. Boys (lit.), 1837:

Vista general de la Mezquita-Catedral (col. particular)

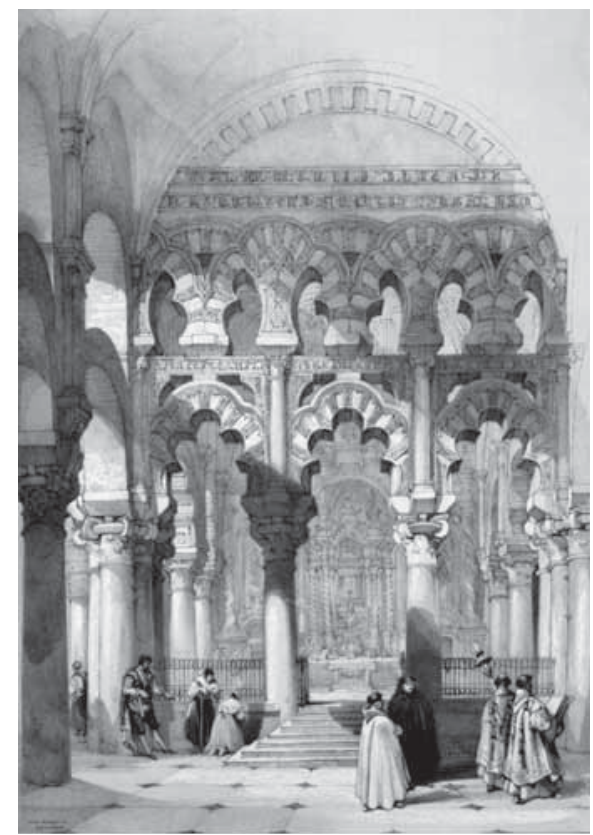

Fig. 12. David Roberts (dib.) / T. S. Boys (lit.), 1837:

Capilla en la Mezquita-Catedral (col. particular) 
también reflejado en la posterior litografía. Otro grabado muestra la nave principal, entonces con bóvedas, y al fondo los arcos de la macsura, fielmente dibujada. Existe una versión de dicha vista en óleo (1849) en Leicester Galleries. También cabe destacar un bello óleo con el entorno del Mihrab (1838) conservado en el Museo del Prado de Madrid, cuyo dibujo previo, tomado in situ (1833), refleja con precisión el lugar ${ }^{83}$. Y una acuarela que detalla el Mihrab se publicó como viñeta (1835), al igual que otra vista de la Capilla Real.

Las bellas vistas de Roberts fueron plagiadas en variadas obras que lógicamente tienen menos interés documental, como el libro de Manuel Galo de Cuendías $(1847,1849,1851,1853)^{84}$, el de Tommaseo Niccolo $(1857)^{85} \mathrm{u}$ otros muchos, algunos con bastantes reediciones, e incluso en nuestros días se siguen reproduciendo o plagiando para ilustrar nuevas publicaciones.

\section{Adrien Dauzats (h. 1836-1838)}

Hacia 1836 el barón Taylor viajó de nuevo a España con el encargo del rey Luis-Felipe de Francia de formar una colección de pintura española, junto al pintor Adrien Dauzats (1804-1868) que realizó valiosas imágenes de diversas ciudades. Se tienen referencias de casi una docena de vistas sobre Córdoba catalogadas por Guinard ${ }^{86}$, aunque en su mayor parte están en paradero desconocido. Tres se dedicaron al entorno urbano: un dibujo del puente con la Mezquita-Catedral al fondo ${ }^{87}$, también en versión óleo y una acuarela de la puerta del Puente. Y ocho vistas son del interior del monumento: una litografía, cuatro acuarelas (una de la capilla de Villaviciosa), tres óleos ${ }^{88}$, más detalles. Además

${ }^{83}$ Guiterman y Llewellyn, David Roberts, pp. 60 y 108, cat. 87.

${ }^{84}$ Cuendias, Spanien und die Spanier... Hubo ediciones en alemán, francés, italiano, sueco e inglés; véanse algunas en Besas, Compendium of German-languaje books of travels...pp. 174-178.

${ }_{85}$ Tommaseo, Geografia storica moderna universale...

${ }^{86}$ Guinard, Dauzats et Blanchard $\ldots \mathrm{n}^{\circ} 52$ a 62, pp. 337-339, plancha XVII. Plessier, Adrien Dauzats... Catalogue... pp. 118-123, 128 y 174.

${ }^{87}$ Royal Collection Trust - Windsor Palace (inv KL 13197) [https://www.royalcollection.org.uk/collection/search\#/3/collection/913197/a-view-of-cordoba] [consultado 27-082017]

${ }^{88}$ Un óleo del interior (1858) se localiza en Blois (Francia), Musée des Beaux-Arts, inv. 387.

Al-Qantara XL 1, 2019, pp. 135-183 ISSN 0211-3589 doi: https//doi.org/10.3989/alqantara.2019.005 
se tienen referencias de dos obras de su acompañante, el pintor Pharamond Blanchard (1805-1873) con el Mihrab y la capilla de Villavi$\operatorname{ciosa}^{89}$.

\section{Nicolás Chapuy (h. 1842)}

Nicolás Chapuy (1790-1858) fue un arquitecto, dibujante y litógrafo que entre 1825 y 1830 publicó muchas vistas de catedrales francesas. Viajó a España junto a Girault de Prangey en 1832-1833. Un nuevo viaje, hacia 1840-1841, daría lugar a una hermosa colección de setenta y dos vistas que salieron de la prestigiosa imprenta Lemercier de París como láminas sueltas hacia 1842, con el título L'Espagne. Vues des principales villes de ce royaume, dessinees d'apres nature par Cha-

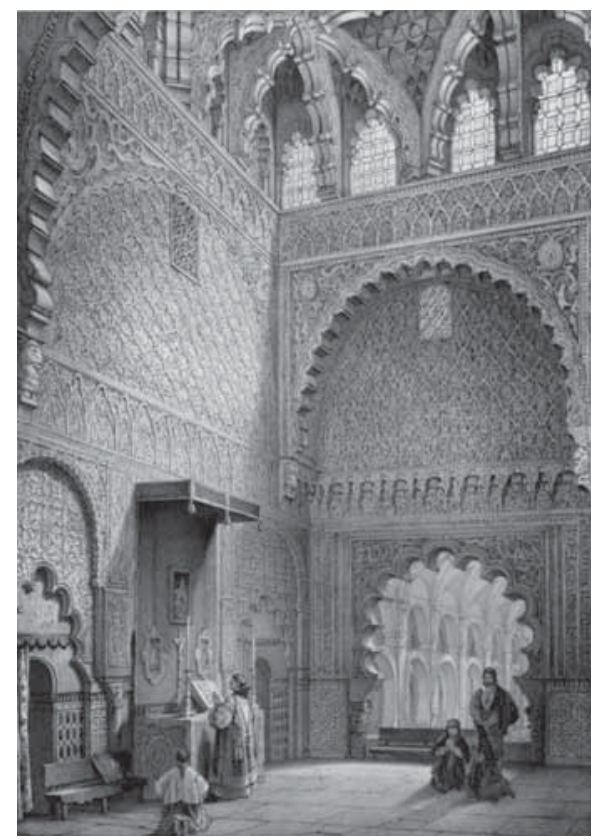

Fig. 13. Chapuy (dir.) / Asselineau (dib./ lit.), h. 1842:

Capilla en la Mezquita-Catedral (col. particular)

${ }^{89}$ Guinard, Dauzats et Blanchard... p. 402. 
$p u y^{90}$. De las cerca de treinta láminas sobre paisajes urbanos andaluces, dos son de Córdoba, ambas con el río y la Mezquita-Catedral.

Chapuy también fue artífice de otras importantes colecciones de láminas con ciudades y monumentos de diversos países. Una de ellas, Le Moyen Age Pittoresque (1838-1841) ${ }^{91}$ incluye dieciocho vistas de España, entre ellas la capilla de Villaviciosa y otro interior de la Mezquita-Catedral con la firma del prestigioso dibujante y litógrafo Léon Augusto Asselineau (1808-1889) (Fig. 13). En una colección similar titulada Le Moyen Age Monumental et Archeologique (1844-1851) ${ }^{92}$, con cuarenta y una vistas de España, aparece otro interior del monumento cordobés.

Debe advertirse que desde 1839 se propagó con rapidez el uso del daguerrotipo, que Chapuy pudo usar para elaborar unas vistas tan detalladas y precisas, igual que otros autores hacían por entonces, en lo que puede considerarse como los inicios de una nueva etapa en la historia de la producción de imágenes apoyadas con técnicas fotográficas.

\section{Jenaro Pérez Villaamil (h. 1838-1844)}

Jenaro Pérez Villaamil y d'Huguet (1807-1854), fue un pintor muy influido por David Roberts, que obtuvo la primera cátedra de paisaje en España, en la Real Academia de San Fernando de Madrid, de la que sería director. Publicó en tres tomos una bella colección de litografías titulada España Artística y Monumental (París, 1842, 1844, 1850) con destacados monumentos españoles entre los que aparece una vista interior de la Mezquita-Catedral, elaborada por el prestigioso litógrafo Jules Arnout ${ }^{93}$.

En un díptico con vistas de España recientemente adquirido y restaurado por el Museo del Prado aparece un interior de la Mezquita, y además pintó otros interiores ${ }^{94}$. En el catálogo de su obra de Arias An-

90 Véase el índice de láminas en Cabra Loredo, España en la litografía romántica... pp. 136-138.

91 Chapuy, Le Moyen Age Pittoresque... 5 tomos.

92 Chapuy, Le Moyen Age Monumental et Archeologique... 3 tomos.

93 Pérez Villaamil (dib.) y Escosura (texto), España artística y monumental... tomo 2.

94 Barón, Genaro Pérez Villaamil. Díptico con vistas... pp. 30-31. 
glés se menciona una pequeña tabla muy fantaseada y dos dibujos de la Alhambra, de los que uno, datado en 1838, no corresponde a Granada sino al monumento cordobés ${ }^{95}$.

\section{François Antoine Bossuet (h. 1841-1858)}

El pintor belga François Antonie Bossuet (h. 1800-1889) fue profesor de Perspectiva en la Academia de Bellas Artes de Bruselas entre 1855 y 1876 y acometió vistas de ciudades de España e Italia ${ }^{96}$. Un dibujo original suyo de Granada, conservado en una colección privada, fechado y firmado en 1841, se realizó in situ con bastante precisión, pero sus pinturas posteriores sobre paisajes de Granada, Sevilla y Córdoba resultaron bastante idealizadas. Una, datada hacia $1845-50$ y adquirida por el Museo de Bellas Artes de Córdoba en 2003, fue plagiada de un grabado de Roberts y es similar a otra versión localizada en el Victoria Albert Museum de Londres ${ }^{97}$. Ambas tienen bello colorido, pero la Mezquita-Catedral y el puente están desproporcionados. En 2017 se ha subastado un óleo suyo fechado en $1858^{98}$, con la vista desde el lado opuesto del río.

\section{Eduard Gerhardt (h. 1849-1851)}

El importante pintor y litógrafo alemán Eduard Gerhardt (18131888) fue enviado a España y Portugal por Federico Guillermo IV de Prusia en 1848. En Sevilla contactó con los duques de Montpensier, siempre deseosos de tratar con buenos artistas para adquirir sus obras, y les acompañaría en sus desplazamientos por Andalucía, como reportero gráfico, acometiendo vistas muy bellas, detalladas y bastante precisas.

95 Arias Anglés, Enrique, El paisajista romántico Jenaro Pérez Villaamil, p. 279, cat. 249 y 474, fig. 102 y 173. El dibujo sobre Córdoba se conserva en el Museo Provincial de Pontevedra. 198-199

96 Benezit, Dictionnaire critique et documentaire des peintres... (1976) tomo II, pp.

97 Victoria Albert Museum, museum number 1071-1886.

98 Casa de subastas Christie's, 13-junio-2017. 
Sobre Córdoba realizó dos acuarelas del interior de la MezquitaCatedral fechadas en $1849^{99}$. Además, la familia Orleans-Borbón conserva una exquisita colección de catorce acuarelas de Gerhardt sobre Granada, Sevilla y Córdoba ${ }^{100}$, con otros dos interiores de la MezquitaCatedral: una fechada en 1850 con la capilla de Villaviciosa, de la que se conoce una variante con distintos personajes datada en $1858^{101}$; y la otra en 1851 con el Mihrab y similar punto de vista a una de 1849, pero con diferentes figuras.

\section{Alfred Guesdon (1853)}

Las vistas aéreas del arquitecto Alfred Guesdon (1808-1876) sobre Francia, Italia, España y Suiza constituyen un motivo de gran interés por su destacada belleza, por reflejar fielmente importantes ciudades de la época y por los interrogantes que plantea su construcción gráfica usando planos, fotografías o globos aerostáticos. Las veinticuatro vistas españolas de Guesdon se publicaron en París como láminas sueltas bajo el título L'Espagne a vol d'odiseau (h. 1853-1855) ${ }^{102}$.

La gran precisión de la vista de Córdoba, cuyo dibujo original está fechado en 1853, se constata al compararla con el plano de Montis de $1851^{103}$. Las iglesias cordobesas constituyen los principales hitos urbanos, entre los que destaca la Mezquita-Catedral, con detalles de los lucernarios en cubiertas, la vegetación del patio de los Naranjos (Fig. 14) y otros pormenores que corroboran el gran valor documental de esta imagen, que integró de forma magistral el dibujo tradicional y los más avanzados medios técnicos del momento.

99 Gebauer Spanien Reiseland Deutscher... pp. 45-47, 90-91.

100 González Barberán, Eduard Gerhardt y los duques de Montpensier (1849-1851).

101 Colección privada Rhineland [http://www.dr-moeller-kunst.de/en/artists-and-publications/4/34/ [consultado 25-08-2017]

102 Guesdon, L'Espagne a vol d'odiseau, lámina no 19.

103 Gámiz Gordo y García Ortega, "La vista aérea de Córdoba dibujada por Alfred Guesdon en 1853". 


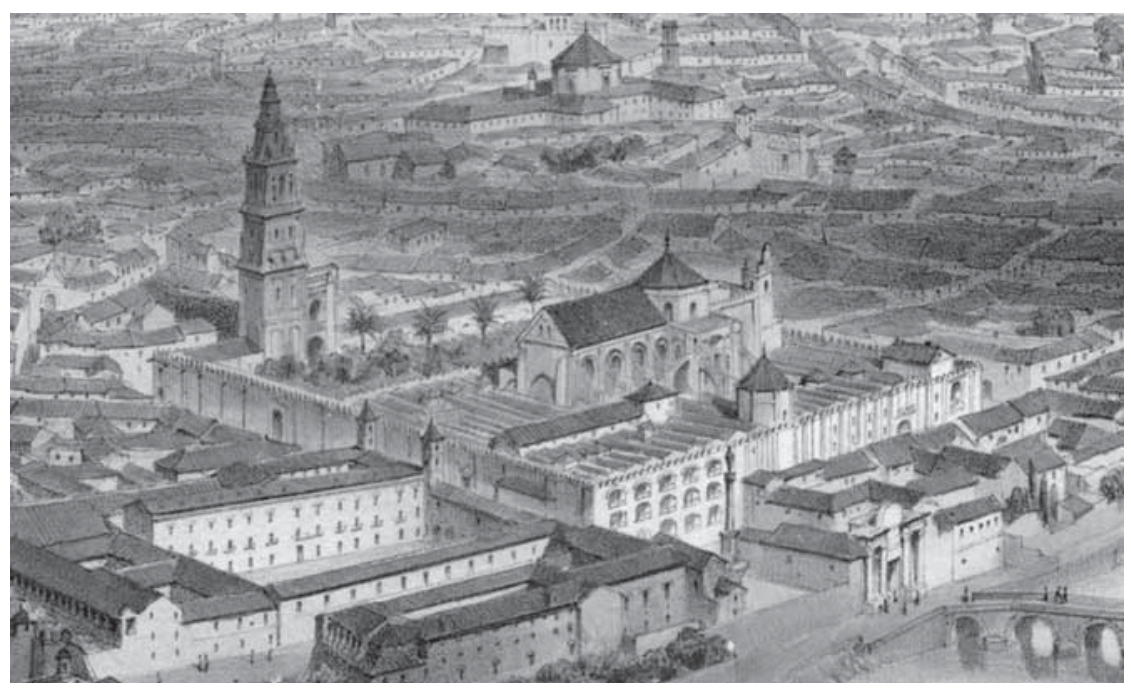

Fig. 14. Alfred Guesdon (dib./ lit.), 1853:

Detalle de la Mezquita-Catedral en vista aérea de Córdoba (col. particular)

\section{Francisco Javier Parcerisa (1855)}

Francisco Javier Parcerisa (1803-1875) fue autor de una extensa obra muy citada en la historiografía del arte español del XIX, Recuerdos y bellezas de España ${ }^{104}$, publicada hacia 1839-1865 en doce tomos con cerca de quinientas litografías.

El tomo de Córdoba, publicado en 1855, comprende veintiocho vistas, de las que doce se dedicaron a la Mezquita-Catedral: seis sobre portadas exteriores y patio, más seis de interiores. Además, se incluyeron dos planos de planta, uno de ellos con la ubicación de los puntos de vista de las láminas. Frente a las imágenes ya citadas de Prangey, Roberts, Lewis u otros que se centraron en el pasado islámico español, Parcerisa incluyó vistas de iglesias (san Lorenzo, santa Marina y san Miguel) y hospitales, más otros edificios de la ciudad y detalles de Medina Azahara.

Para elaborar tantas láminas se emplearían primitivos recursos fotográficos, debiendo considerarse que por entonces la veracidad y la

104 Parcerisa, Recuerdos y bellezas de España. 
exactitud daban prestigio a las publicaciones ${ }^{105}$. Parcerisa copió algunas vistas de Prangey, pionero en el uso del daguerrotipo en París, aunque se desconoce la relación que pudo existir entre ambos.

\section{Los Monumentos Arquitectónicos de España (h. 1852-1881)}

Como colofón cabe destacar una de las más importantes iniciativas editoriales del siglo XIX en nuestro país, un catálogo gráfico titulado Los Monumentos Arquitectónicos de España ${ }^{106}$, que al igual que la obra Parcerisa rebasa la delimitación temporal aquí propuesta hacia 1850. Sus orígenes se remontan a los ejercicios de estudiantes de Arquitectura que en 1849 y 1850 viajaron a distintas provincias españolas para dibujar sus monumentos. Poco después, con la protección de la reina Isabel II, los trabajos se encomendaron a destacados profesores, ayudados por alumnos, pintores y fotógrafos. Su publicación como láminas sueltas tuvo lugar hacia 1856-1882. Fueron estampadas en la Calcografía Nacional con varias técnicas: aguafuerte y buril, aguatinta, litografía o cromolitografía. Los textos fueron impresos en español y francés.

En la primera entrega de 1859 se decía que la obra abrazaría todas las edades, estilos y comarcas, usando el ventajoso arte de la fotografía y todos los medios necesarios para su exactitud. Se pretendían reunir los principales monumentos de las tres culturas existentes en suelo español, pagana, mahometana y cristiana, utilizando dicha nomenclatura para clasificar las láminas. Hasta 1881 se realizaron doscientas ochenta y una estampas con monumentos de veinticuatro provincias españolas.

Sobre Córdoba hubo veintitrés láminas, todas de gran belleza y precisión: una planta general, alzados y detalles de elementos arquitectónicos, como portadas, arquerías, bóvedas, capiteles y fragmentos de ornamentación ${ }^{107}$. Tan solo se realizó una vista, sobre la nave principal del Mihrab, que puede considerarse como una de las más bellas en la

\footnotetext{
105 Tan solo se ha localizado el nombre del fotógrafo en una lámina del tomo de Sevilla y Cádiz. Véase Alonso Martínez, "Recuerdos y Bellezas de España y su relación con el medio fotográfico".

106 Real Academia de Bellas Artes de San Fernando de Madrid (ed.), Los monumentos Arquitectónicos...

107 Se reproducen en Nieto Cumplido y Luca de Tena, La Mezquita... n n 28-50. 
historia gráfica del monumento. Recientemente se han publicado unos veinte dibujos preparatorios de exquisita calidad que se conservan en la Real Academia de Bellas Artes de San Fernando de Madrid ${ }^{108}$.

\section{Conclusiones}

La presente investigación aporta abundantes datos, a modo de síntesis, sobre un rico patrimonio gráfico que por primera vez aquí se reúne y se valora, con la intención de fomentar nuevas investigaciones sobre la Mezquita-Catedral de Córdoba. No se ha pretendido cerrar un listado de imágenes del monumento, ni su valoración definitiva, sino aportar amplias referencias sobre dichas fuentes gráficas, cuyo estudio podrá progresar en el futuro, complementándose con otras fuentes histórico-literarias y con el análisis de la propia realidad arquitectónica.

Para concluir esta aproximación al corpus documental aportado, seguidamente se reseñan, a modo de recapitulación final, algunas de las valoraciones o cuestiones de mayor interés ya apuntadas.

No se conocen dibujos de Córdoba en tiempos islámicos. Tras unas primeras imágenes simbólicas, es muy importante la panorámica de Wyngaerde de 1567, que detalla las obras renacentistas en el monumento y otros pormenores urbanos y arquitectónicos (campanario, lucernarios, etc.). Fue el primer dibujo desde uno de los puntos de vista más representativos de la ciudad a lo largo de su historia gráfica, con el Guadalquivir y el puente romano en primer plano, la Mezquita-Catedral como protagonista y Sierra Morena al fondo. Desde una ubicación cercana dibujaron otros importantes autores del siglo XIX: Laborde, Murphy, Roberts, Prangey... ${ }^{109}$.

La vista de Wyngaerde es parecida a la publicada en 1617 en el $\mathrm{Ci}$ vitatis Orbis Terrarum, atribuida por error a Hoefnagel, pues incluye las Caballerizas Reales fundadas en 1570 y éste concluyó su viaje por España en 1567. Una variante de esta vista, que ha sido considerada como copia del Civitatis en el XVII, menciona en su cartela el privile-

108 Almagro Gorbea (ed.), El legado de al-Ándalus... p. 334-369.

109 Entre los artistas que dibujaron la Mezquita-Catedral desde este lugar, al cerrar estas conclusiones se ha localizado un excepcional y preciso dibujo a lápiz del pintor Wilhelm Meyer titulado "Cordoue, La Caraola" fechado el 25 de febrero de 1846. Kunsthaus Zürich, Collection of Prints and Drawings, L 73- Fol. 16. http://wilhelmmeyer.transculturalstudies.ch/en/wilhelm-meyer/meyers-studies/cordoba.html 
gio otorgado por el Papa Sixto V y debe datarse entre 1585 y 1590. Dicha vista fue reeditada y plagiada en variadas obras que tuvieron una notable difusión en Europa y que se reseñan aquí por primera vez: Janssonius, Valegio, Meisner, Zeiller, Coronelli, Aa, Álvarez de Colmenar y Fernández Palomino.

En 1668 Baldi realizó una panorámica desde el meandro del Guadalquivir. Desde dicho entorno Swinburne, Roberts y Chapuy también dibujaron el perfil urbano cordobés con la Mezquita-Catedral en la lejanía. Entre los siglos XVII y XVIII hubo otras representaciones esquemáticas con limitado valor documental, y aunque serían necesarios muchos dibujos para las importantes obras cristianas acometidas, éstos no se han conservado.

El primer plano de planta del monumento conocido es un óleo anónimo fechado en 1741, que incorpora un alzado de la nueva torre-campanario y una amplia leyenda descriptiva. En 1767, por encargo de la Real Academia de Bellas Artes de San Fernando, se dibujaron las primeras plantas y secciones a escala de la Mezquita-Catedral, publicados en 1787. Por primera vez se realizaba una interpretación arqueológica del monumento y una hipótesis de su planta en tiempos islámicos, sin añadidos cristianos, que fue objeto de plagios posteriores. Sus abundantes pormenores resultan de gran interés para analizar las restauraciones de los siglos XIX y XX.

La primera vista interior del monumento fue dibujada por Swinburne en su viaje por España hacia 1775-76 y publicada en 1779. Refleja de forma esquemática la nave central hacia el Mihrab con las bóvedas que entonces tenía.

El primer plano a escala de la ciudad de Córdoba fue elaborado con fines civiles por Karwinsky y Rillo en 1811, durante la ocupación francesa. Hasta ahora se conocía por reproducciones incompletas, pero ha sido rigurosamente digitalizado en una reciente tesis doctoral (2017) que abrirá paso a nuevas investigaciones urbanas.

En la primera mitad del XIX fueron muchos los viajeros y artistas que dibujaron la Mezquita-Catedral. La primera colección de vistas fue publicada en 1812 por Alexandre Laborde, con atractivas imágenes fieles a la realidad, ejecutadas con cámara oscura. Menos fiables, pero no exentas de valor, fueron las láminas de Murphy aparecidas en 1813. También cabe destacar las numerosas vistas de Taylor publicadas entre 1826 y 1832 , algunas con ciertas desproporciones. 
La breve estancia de Richard Ford en Córdoba en 1833 dio lugar a pocas vistas en comparación con sus abundantes dibujos sobre Sevilla o Granada. Su amigo, el pintor Lewis, publicó dos exquisitas litografías del interior de la Mezquita-Catedral. Por otra parte, Girault de Prangey aportó diez láminas ejecutadas con bastante rigor y sensibilidad. Y apenas se conocen las interesantes vistas del pintor Dauzats, en gran parte en paradero desconocido.

David Roberts fue autor de las más bellas vistas del monumento cordobés, que además tienen un importante valor documental. Entre ellas cabe destacar una litografía con el puente romano en primer plano, otra de la capilla de Villaviciosa que detalla el retablo que allí existió y un óleo del Mihrab hoy conservado en el Museo del Prado.

Chapuy publicó hacia 1842 dos precisas vistas urbanas de Córdoba más interiores del monumento, posiblemente usando daguerrotipos. Además, deben considerarse las imágenes de Villaamil, otras de Bossuet algo desproporcionadas y las vistas de Gerhartd, fidedignas y poco conocidas.

Después de 1850, además de la precisa vista aérea de Guesdon, cabe destacar dos grandes obras gráficas sobre el patrimonio arquitectónico español que usarían primitivas fotografías para favorecer su exactitud: las láminas de Parcerisa y los Monumentos Arquitectónicos de la Real Academia de Bellas Artes de San Fernando.

El conjunto de imágenes reseñado puede ampliarse con otras muchas hasta nuestros días: con las visiones de muchos artistas que captaron las luces y sombras arquitectónicas del monumento, con los planos y dibujos de sus obras de restauración, y con los planos históricos de la ciudad. Además, la llegada de la fotografía dio lugar a nuevas vistas que documentaron el monumento de forma fehaciente.

No debe olvidarse que los planos solían responder a convenciones geométricas y a un lenguaje gráfico con vocación de objetividad, mientras que las vistas solían apartarse de las estrictas reglas de la perspectiva, con lenguajes gráficos más subjetivos o personales. Por ello, para interpretarlas debe atenderse a su contexto y a otras obras de sus autores, en relación con las técnicas usadas, que con el paso del tiempo fueron avanzando en verosimilitud y precisión.

Asimismo, debe considerarse la localización de puntos de vista o miradores de interés visual. La Mezquita-Catedral fue dibujada en muchos casos desde las cercanías del Guadalquivir, desde sus calles ad- 
yacentes o su patio, con su torre como referencia visual. En las vistas interiores fueron protagonistas sus arquerías, la capilla de Villaviciosa, la capilla Real o la nave hacia el Mihrab. La acumulación de vistas en ciertos lugares conformaría un sustrato de imágenes emblemáticas que pueden considerarse como verdaderos símbolos del monumento.

Sería deseable que todas ellas pudiesen publicarse con alta resolución en un futuro próximo, para que sus pormenores sean estudiados por investigadores con variados intereses y disfrutadas por todo tipo de público, pues ofrecen datos elocuentes y a veces de gran belleza. No debe olvidarse que muchas tuvieron una gran difusión en el contexto europeo de su época, de forma que el público culto pudo contemplar paisajes y lugares apenas conocidos antes de la aparición de la fotografía.

Por tanto, el corpus gráfico reseñado constituye un patrimonio de incalculable valor, una verdadera seña de identidad de la Mezquita-Catedral de Córdoba y un referente imprescindible para conocer sus transformaciones urbanas y arquitectónicas.

\section{Bibliografía $^{110}$}

Aa, Pieter van der (ed.), Beschryving van Spanjen en Portugal, waar in, op the naauwkeurigste, al het geene, dat, zoo ten opzigte van hunnen ouden, als tegenwoordigen staat..., Leiden, 1707 [BNE sig. ER/2405].

Aa, Pierre van der (ed.), La Galerie Agreable du Monde: Tome Second, Du Roïaume D'Espagne, Leiden, Marchand Libraire, h. 1720, tomo II, [BNE sig. $\mathrm{ER} / 2055$ (21)-ER/2055 (89)].

Aa, Pierre van der (ed.), Les Royaumes d'Espagne et de Portugal, représentés en tailles-douces tres exactes, dessinees sur les lieux mêmes, qui comprennent les principales villes, forteresses, montagnes, églises, monastères ... et autres choses dignes de remarque, avec les cartes géographiques tant générales que particulieres de cesdeux royaumes, Leiden, chez Pierre Van der Aa, Marchand Libraire, [h. 1730] [BNF sig. FRBNF40363215].

110 Abreviaturas utilizadas: BNE (Biblioteca Nacional de España, Madrid), BNF (Biblioteca Nacional de Francia, París), BNMV (Biblioteca Nazionale Marciana, Venecia), RBPN (Real Biblioteca Patrimonio Nacional, Madrid), BA (Biblioteca de la Alhambra, Granada), BAG (Biblioteca de Andalucía, Granada), BRN (Biblioteca Real Neerlandesa, La Haya), ZTUB (Zentralbibliothek der Technischen Universitat, Berlín), BFUB (Bibliothek der Freiren Universität, Berlín). 
Almagro Gorbea, Antonio (ed.), El legado de al-Ándalus. Las antigüedades árabes en los dibujos de la Academia, Madrid, Real Academia de Bellas Artes de San Fernando y Fundación Mapfre, 2015.

Álvarez de Colmenar, Juan y Aa, Pierre Vander (ed.), Les delices de l'Espagne \& du Portugal: où l'on voit une description exacte des antiquitez, des provinces, des montagnes...: de la réligion, des moeurs des habitans, de leur fêtes... dessinées sur les lieux mêmes par Juan Alvarez de Colmenar, Leiden, chez Pierre Vander Aa, 1707, tomo 3 [BNE sig. ER/3564 V. 3].

Álvarez de Colmenar, Juan, Annales d'Espagne et de Portugal: contenant tout ce qui s'est passé de plus important dans ces deux royaumes \& dans les autres parties de l'Europe .... avec la description de tout ce qu'il y a de plus remarquable en Espagne \& en Portugal ... par Don Juan Alvarez de Colmenar, Amsterdam, chez François L'Honoré \& fils, 1741, tomo 2 [BNE sig. 2/66165 V.2].

Alonso Martínez, Francisco, "Recuerdos y Bellezas de España y su relación con el medio fotográfico", Archivo Español de Arte, no 286, 1999, pp. 192-198.

Arias Anglés, Enrique, El paisajista romántico Jenaro Pérez Villaamil, Madrid, Consejo Superior de Investigaciones Científicas, Centro de Estudios Históricos, Dpto. de Ha del Arte "Diego Velázquez", 1986.

Bacler d'Albe, Louis Albert, Souvenirs pittoresques du general Bacler d'Albe, París, Engelmann, h. 1820 [RBPN sig. GRAB/321].

Báez, José María, Imágenes y visiones de Córdoba, Sevilla, Los Sentidos Ediciones, 2014.

Barón, Javier, Genaro Pérez Villaamil. Díptico con vistas de ciudades españolas, Madrid, Museo Nacional del Prado, 2014.

Benezit, E., Dictionnaire critique et documentaire des peintres, sculpteurs, dessinateurs et graveurs, Paris, Librairie Gründ, 1976, 10 tomos.

Besas, Peter, Compendium of German-languaje books of travels in Spain 17501900, Madrid, Ediciones la Librería, 2010.

Bourgoing, Jean François, Tableau de L'Espagne Moderne, París, 1807 [London, reprinted for John Stockdale, 1808], tomo III [BNE sig. GMm/602-605]

Braun, Georg y Hogenberg, Franz (ed.), Civitates Orbis Terrarum, Colonia y Amberes, 1572, 1575, 1581, 1588, 1598, 1617, 6 tomos [tomo VI, BNE sig. GMG/755]

Calvo Capilla, Susana, "El entorno de la mezquita aljama de Córdoba antes y después de la conquista cristiana”, en Eduardo Carrero y Daniel Rico (ed.), Catedral y ciudad medieval en la península Ibérica, Murcia, Nausicaa, 2005, pp. 9-34.

Calvo Capilla, Susana, "Primeras mezquitas de Al-Andalus a través de las fuentes árabes”, Al-Qantara, XVIII, 1, 2007, pp. 143-179 [http://al-qantara.revistas. csic.es/index.php/al-qantara/article/view/34/28][consultado 02/09/2017]

Caro Baroja, Julio, "La ciudad de Córdoba desde la orilla izquierda del Guadalquivir, según un sello del siglo XIV”, Al-Andalus, XXIII, 1, 1958, pp.197-ss. 
Cabra Loredo, María Dolores y varios, España en la litografía romántica. Una puerta abierta al mundo, Madrid, Museo Romántico y Frame, 1994.

Casanovas i Miró, Jordi, y Quilez i Corella, Francesc M., El viatge a Espanya d'Alexandre de Laborde. Barcelona, Museu Nacional d'Art de Catalunya, 2006.

[Catálogo exposición], Imagen romántica de España, Madrid, Ministerio de Cultura, 1981, 2 tomos.

[Catálogo exposición], El Viaje a Compostela de Cosme III de Médicis, Xunta de Galicia, 2004.

Cea Garcia, Juan Ignacio de: Análisis cartográfico y representativo del plano urbano de Córdoba de 1811. Plano de los Franceses. De la ciudad conocida a la ciudad representada, tesis doctoral inédita, dirigida por J. A. Barrera Vera y A. Ramírez de Arellano Agudo, Universidad de Sevilla, 2017.

Chapuy, Nicolas y Moret, Philippe, Le Moyen Age Pittoresque. Monuments et fragmens d'architecture, meubles, armes armures et objets de curiosités du Xe au XVIIe siècle, París, Veith et Hauser, 1838-1841, 5 tomos [ZTUB, sig. 2B1324/3].

Chapuy, Nicolas, L'Espagne. Vues des principales villes de ce Royaume. Dessinees d'apres nature par Chapuy, París, Bulla, h. 1842 [láminas sueltas] [RBPN sig. IX/M/106 (1-72)].

Chapuy, Nicolas, Le Moyen Age Monumental et Archeologique: vues et details des monumets les plus remarquables de l'Europe depuis le VIe jusqu'au XVIIIe siècle Lithographies par les principaux artistes d'après les dessins de Chapuy Cinq part contenant 444 planches in fol., París, Levy fils., 1844-1851, 3 tomos [BNE sig. BA/943 v.1, BA/944 v.2, BA/945 v.3].

Coronelli, Vicenzo María, Teatro della guerra, Gran Bretagna, Spagna, Portogallo, Venecia, 1706, tomo II, [BNMV sig. 203.d.208].

Cosano Moyano, Francisco, Iconografía de Córdoba, Córdoba, Caja Sur, 1999.

Cuendias, Emanuel von [Manuel Galo de], Spanien und die Spanier, ihre Sitten, Trachten, Volkssagen und Legenden, Bau-und Kunstdenkmäler, Bruselas \& Leipzig, Carl Muquardt, 1847 [BNF sig. FRBNF30290308]

Espinalt y García, Bernardo y Fernández Palomino, Juan (dib.), Atlante español, ó Descripcion general geográfica, cronológica, è histórica de España, por reynos y provincias... adornado de estampas finas, que demuestran las vistas perspectivas de todas las ciudades, Madrid, imprenta de Pantaleón Aznar, h. 1779-87, tomo XI [BNE sig. GMM/202].

Farinelli, Arturo, Viajes por España y Portugal. Desde la Edad Media hasta el siglo XX. Nuevas y antiguas divagaciones bibliográficas, Florencia, Academia D'ltalia, 1942-1946, 3 tomos.

Ferrario, Jules, Le Costume, Ancien et Moderne, Milan, de l'Imprimerie de l'Editeur, 1825 [col. particular].

Ford, Richard, Hand-book for Travellers in Spain, Londres, Murray, 1845, 2 tomos [BNE sig. BA/7822 v. 1, BA/8035 v. 2]. 
Foulche Delbosch, Raymond, Bibliographie des voyages en Espagne et en Portugal, Madrid, Julio Ollero editor [París: H. Welter], 1991 [1896].

Gail, Wilhelm, Erinnerungen aus Spanien. Nach der Natur auf Stein gezeichnete Skizzen aus dem Leben in den Provinzen Catalonien, Valencia, Andalusien, Granada und Castilien, mit Fragmenten maurischer und altspanischer Architektur und Veduten nebst erläuternden Auszügen aus dem Tagebuche des Herausgebers, Munich, Literarisch Artistische Anstalt, h. 1837 [BNE sig. ER/5760].

Gailhabaud, Julio, Monumentos antiguos y modernos: coleccion que constituye la historia de la arquitectura de los diferentes pueblos en todas sus épocas, reunida por primera vez en una obra completa ... / por Omard, Champollion Figeac, Langc ... [et al.]; acompañan láminas grabadas y dibujadas por distintos arquitectos y artistas, Madrid, J. Boix, 1845 [BNE sig. ER/848 V.1].

Galera i Monegal, Monserrat, Antoon van den Wijngaerde, pintor de ciudades y de hechos de armas en la Europa del Quinientos. Cartobibliografía razonada de los dibujos y grabados, y ensayo de reconstrucción documental de la obra pictórica, Fundación Carlos de Amberes, Institut Cartografic de Catalunya, 1998.

Gámiz Gordo, Antonio, Alhambra. Imágenes de ciudad y paisaje (hasta 1800), Granada, Fundación El Legado Andalusí y Patronato de la Alhambra, 2008.

Gámiz Gordo, Antonio, "Las vistas de España del viajero David Roberts, pintor de paisajes y arquitecturas, hacia 1833" EGA Expresión Gráfica Arquitectónica, $\mathrm{n}^{\mathrm{o}}$ 15, 2010, pp. 54-65. https://doi.org/10.4995/ega.2010.992

Gámiz Gordo, Antonio, "Los dibujos originales de los palacios de la Alhambra de J. F. Lewis (h. 1832-33)", EGA Expresión Gráfica Arquitectónica, n 20, 2012, pp. 76-87. https://doi.org/10.4995/ega.2012.1406

Gámiz Gordo, Antonio y Anguís Climent, Diego, "Edificaciones fluviales cordobesas. La imagen gráfica como medio de conocimiento de construcciones históricas", en Actas del Cuarto Congreso Nacional de Historia de la Construcción, Cádiz, 2005, tomo 1, pp. 429-438.

Gámiz Gordo, Antonio y García Ortega, Antonio Jesús, "Las iglesias cordobesas en tres imágenes de la ciudad entre los siglos XVI y XIX", EGA Expresión Gráfica Arquitectónica, no 14, 2009, pp. 158-165.

Gámiz Gordo, Antonio y García Ortega, Antonio Jesús, "Vistas del Alcázar de los Reyes Cristianos de Córdoba hasta mediados del siglo XIX", Reales Sitios. Revista de Patrimonio Nacional, $\mathrm{n}^{\circ}$ 193, 2012, pp. 4-19.

Gámiz Gordo, Antonio y García Ortega, Antonio Jesús, "La primera colección de vistas de la Mezquita-Catedral de Córdoba en el Voyage de Laborde (1812)", Archivo Español de Arte, vol. 85, no 338, 2012, pp. 105-124. https://doi.org/10.3989/aearte.2012.v85.i338.500

Gámiz Gordo, Antonio y García Ortega, Antonio Jesús, “David Roberts en Córdoba. Vistas de paisaje y arquitectura hacia 1833", Archivo Español de Arte, vol. $88, \mathrm{n}^{\mathrm{o}} 352,2015$, pp. 367-386. https://doi.org/10.3989/aearte.2015.23 
Gámiz Gordo, Antonio y García Ortega, Antonio Jesús, "La vista aérea de Córdoba dibujada por Alfred Guesdon en 1853", Archivo Español de Arte, vol. 91, nº 361, 2018, pp. 29-45. https://doi.org/10.3989/aearte.2018.03

Gámiz Gordo, Antonio y García Ortega, Antonio Jesús, “Dibujos de Richard Ford en Córdoba (1831)", Arte y Ciudad. Revista de Investigación, n $^{\circ} 13,2018$, p. 143-158. http://dx.doi.org/10.22530/ayc.2018.N13.471

García Mercadal, José, Viajes de extranjeros por España y Portugal. Desde los tiempos más remotos hasta los comienzos del siglo XX, Valladolid, Junta de Castilla y León, 1999.

García Ortega, Antonio Jesús y Gámiz Gordo, Antonio, "La ciudad de Córdoba en su primer plano: un dibujo esquemático de 1752", Archivo Español de Arte, vol. 83, no 329, 2010, pp. 23-40. https://doi.org/10.3989/aearte.2010.v83.i329.411

García Verdugo, Francisco y Martín López, Cristina, Cartografía y fotografía de un siglo de urbanismo en Córdoba 1851/1958. Ayuntamiento de Córdoba, 1994

Gebauer, Anja Spanien Reiseland Deutscher Maler 1830-1870, Michael Imhof Verlag, 2000.

Gimena Córdoba, Pilar, Forma, espacio y estructura en la transición al Renacimiento cordobés. Tradición e innovación en la obra de Hernan Ruiz "El Viejo” (h. 1479-1547), tesis doctoral inédita, dirigida por Antonio Luis Ampliato Briones, Universidad de Sevilla, 2014.

Girault de Prangey, Philibert, Monuments arabes et moresques de Cordoue, Seville et Grenada, París, Veith et Hauser, Imp. Lemercier Bernard et Cie, 1836-1839 [RBPN sig. IX/M/62].

Girault de Prangey, Philibert, Essai sur l'Architecture des Arabes et des Mores, en Espagne, et Sicilie et en Barbarie, París, A. Hauser, 1841 [BN BA/1571].

González, Antonio Jesús, El laberinto de columnas. Fotografías y fotógrafos en la Mezquita Catedral de Córdoba, 1844-1875, Córdoba, Cabildo de la Santa Iglesia Catedral de Córdoba, 2018.

González Barberán, Vicente, Eduard Gerhardt y los duques de Montpensier (1849-1851), Granada, edición privada, 2000.

Guesdon, Alfred, L'Espagne a vol d'odiseau, París, Hauser y Delarue, París, h. 1853-1855 [BNE sig. INVENT/69194].

Guinard, Paul, Dauzats et Blanchard:peintres de l'Espagne romantique, Burdeos, Presses Universitaries de France, 1967.

Guiterman, Helen y Llewellyn, Briony, David Roberts, Londres, Phaidon Press y Barbican Art Gallery, 1986.

Janssonius, Johannes, Theatrum In quo visuntur Illustriores Hispaniae Urbes, Aliaeque ad Orientem \& Austrum Civitates celebriores, Amstelodami, 1657 [BNE sig. ER/1859 V.7].

Janssonius, Johannes, Toonel der vermaarste koop-steden en handel-plaatsen van den gehele Wereld, Amsterdam, erfg. J. Janssonius van Waesberge, 1682, 2 tomos [BRN sig. 395 B 23]. 
Junguito de Guevara, Antonio (dib.), Libro de Recibimientos de Oficios y Juramentos, Córdoba, Archivo Histórico Municipal, 1744.

Kagan, Richard L. (dir.), Ciudades del siglo de oro. Las vistas españolas de Anton van der Wyngaerde, Madrid, ediciones el Viso, 1986.

Laborde, Alexandre, Voyage pittoresque et historique de l'Espagne, París, 1812, tomo II [BNE sig. BA/2058 V.3].

Lewis, John Frederick, Sketches of Spain \& spanish character made during his tour in that country in the years 1833-34, Londres, C. Hullmandel's, s.a., 1836 [BA sig. A-5 2 11].

López Ontiveros, Antonio, La imagen geográfica de Córdoba en la literatura viajera de los siglos XVIII y XIX, Universidad de Córdoba, Lección inaugural curso 1989-90, 1989.

Luxenberg, Alisa, Secrets and Glory. Baron Taylor and his Voyage Pittoresque en Espagne, Madrid, Centro de Estudios de Europa Hispánica y Hispanic Society of America, 2013.

Meisner, Daniel, Thesaurus sapientiae civilis, sive vitae humanae ac virtutum et vitiorum Theatrum: symbolis aeri incise, Francofurti, 1626 [BNE sig. 3/25240].

Mulvin, Linda S., "An unknown collection of preliminary drawings and extra illustrations prepared for The Arabian Antiquities of Spain by James Cavanah Murphy in the Gennadius Library, Athens", Muqarnas, vol. 35, 2018, pp. 301-348.

Murphy, James Cavanah, The Arabian Antiquities of Spain, Londres, 1813 [BA sig. A-5 3 13].

Nieto Cumplido, Manuel, La Catedral de Córdoba, Córdoba, Caja Sur, 1998.

Nieto Cumplido, Manuel y Luca de Tena Alvear, Carlos, La Mezquita de Córdoba: planos y dibujos, Colegio Oficial Arquitectos de Andalucía Occidental, 1992.

Ortí Belmonte, Miguel Ángel, Córdoba durante la guerra de la independencia (1808-1813), Córdoba, Real Academia de Ciencias, Bellas Letras y Nobles Artes de Córdoba, Imprenta La Comercial, 1930.

Palau y Dulcet, Antonio, Manual de Librero Hispano-Americano. Inventario bibliográfico de la producción científica y literaria de España y de la América Latina desde la invención de la imprenta hasta nuestros días, Barcelona, Librería Anticuaria, 1923-1927, 7 tomos.

Parcerisa, Francisco Javier, Recuerdos y bellezas de España, Madrid, Imprenta de D. José María Repullés, 1855, tomo 8 [BNE sig. ER5177 V.8]

Plessier, Ghislaine, Adrien Dauzats ou la tentation de l'Orient. Catalogue raisonné de l'oeuvre peint, Musée des Beaux-Arts de Bordeaux / William Blake and Co., 1990.

Pérez Villaamil, Genaro (dib.) y Escosura, Patricio de la (texto), España artística y monumental: vistas y descripción de los sitios y monumentos más notables de España obra dirigida y ejecutada por Genaro Perez de Villa-Amil...; texto 
redactado por Patricio de la Escosura, París, Alberto Hauser, 1844, tomo 2 [BNE sig. ER/1717 V. 2]

Piqueras, Juan y Ghaleb Fansa, "La península Ibérica en el gran atlas de al-Idrisi”, Segon Congrés Català de Geografia, Barcelona, Societat Catalana de Geografía, 2008, pp. 465-477.

Ponz y Piquer, Antonio, Viage de España, ó Cartas, en que se da noticia de las cosas más apreciables, y dignas de saberse que hay en ella... por D. Joaquín Ibarra, impresor de Cámara de S. M., 1772-1794, tomos 16 y 17 [1791 y 1792] [RBPN sig. IX/1139 y IX/1140].

Quesada, Luis, Pintores españoles y extranjeros en Andalucía, Sevilla, ediciones Guadalquivir, 1996.

Real Academia de Bellas Artes de San Fernando de Madrid (ed.). Las Antigüedades Árabes de España, Madrid, Imprenta Real, 1787 y 1804, 2 tomos [BA sig. A-5 3 12].

Real Academia de Bellas Artes de San Fernando de Madrid (ed.), Los Monumentos Arquitectónicos de España, Madrid, Calcografía Nacional, h. 1852-1881 [láminas sueltas].

Roberts, David, Picturesque sketches in Spain taken during the years 1832-1833, Londres, Hocgson and Graves, 1837 [BNE sig. ER/1713].

Robertson, Ian, Los curiosos impertinentes. Viajeros ingleses por España, Barcelona, ediciones Serbal, 1988.

Rodríguez Ruiz, Delfín, La memoria frágil, José de Hermosilla y las Antigüedades Árabes de España, Madrid, Colegio Oficial de Arquitectos de Madrid, 1992.

Rodríguez Barberán, Francisco Javier, Gámiz Gordo, Antonio y Robertson, Ian, Richard Ford. Viajes por España (1830-33), Madrid, Real Academia de Bellas Artes de San Fernando y Fundación Mapfre, 2014.

Roscoe, Thomas (texto) y Roberts, David (dib), The tourist in Spain. Andalusia, Londres, R. Jennings, 1838, tomo 2 [BAG sig. ANT-XIX-1775].

Sánchez Rivero, Ángel y Sánchez Rivero, Ángela Maritutti (edición y notas): Viaje de Cósme de Médicis por España y Portugal (1668-1669), Madrid, Sucesores de Rivadeneyra, 1933.

Savonarola, Innocenzo Raffaelle [y Lasor a Varea, Alphonsi], Universus terrarum orbis scriptorum calamo delineatus, hoc est auctorum fere omnium qui de Europae, Asiae, Africae et Americae regnis, provinciis, populis, civitatibus, oppidis... qualibet lingua scripserunt; cum anno, loco et forma editionis eorum uberrimus elenchus... studio et labore Alphonsi Lasor a Varea... Padua, 1713, 2 tomos [RBPN sig. 42040].

Skelton, Raleigh Ashlin (introd.), Georg Braun - Frans Hogenberg, Civitates Orbis Terrarum, Cleveland and New York, World Publishing Co., 1966, 3 tomos.

Swinburne, Henry, Travels through Spain, in the Years 1775 and 1776: in which several monuments of roman and moorish architecture are illustrated by ac- 
curate drawings taken on the spot, Londres, P. Elmsly, 1779 [BNE sig. GMM/2097].

Swinburne, Henry, Picturesque tour through Spain, by Henry Swinburne; embellished with twenty engravings by Watts, Medland, Angus, Mitan, \&c., Londres, J. C. Barnard, 1806 [BNE sig. ER/2455]

Taylor, Isidore, Voyage pittoresque en Espagne, et Portugal, et sur la cote d'Afrique, París, Librairie de Gide Fils, 1826-1832-1860, 3 tomos [BNF département Littérature et art, 4-H-420 (3)].

Tommaseo, Niccolo, Geografia storica moderna universale: corografica politica statistica industriale e commerciale. Scritta sulle traccie di Adriano ed Eugenio Balbi, Marmocchi, Ritter, Roon, Maltebrun, Chauchard, Muntz, Ghoberti, Lavallee, ecc, Milán / Nápoles, Pagnoni / Marghieri, 1857, 3 tomos [BFUB sig. 17 E 311-3]

Torres Márquez, Martín y Naranjo Ramírez, José, "El casco histórico de Córdoba y el primer plano de la ciudad: el Plano de los Franceses de 1811", Eria, n $^{\circ}$ 88, 2012, pp. 129-151.

Valegio, Francesco, Raccolta delle più illustri et famose città di tutto il mondo, Venezia, 1625 [BNMV sig. rari 386, GEO0005746].

Vivian, George, Spanish Scenery, Londres, P. \& D. Colnaghi, 1838 [BNE sig. $\mathrm{ER} / 1700]$.

Zeiller, Martín, Hispaniae et Lusitaniae Itinerarium. Nova et accurata descriptione e iconibusq. novis et elengatibus loca earundem praecipua illustrans, Amstelodami, apud Aegidium Ianssonium Valckenier, 1656 [BNE sig. $\mathrm{GMM} / 2290]$.

Recibido: $13 / 10 / 2017$

Aceptado: 21/08/2019 